\title{
8. Die nachrichtendienstliche Bedeutung der Fotografie und Trophäenfotografien der Verbrechen
}

Im Oktober 1942 erteilte das Oberkommando Weisungen, wie mit den beschlagnahmten feindlichen Unterlagen zu verfahren ist und wie sie zu verwenden sind. Zu diesen zählten alle gesetzlichen Vorschriften, Briefe, Propagandamaterial, Broschüren, Zeitungen, Bücher, insbesondere jedoch Fotografien von Personen, Personengruppen sowie Objekten. ${ }^{1} \mathrm{Zu}$ Beginn der nachrichtendienstlichen Aktivitäten stammten die ersten Angaben aus den Berichten von Mitgliedern der Widerstandsbewegung aus den städtischen Gebieten. Die im Nachrichtendienst tätigen Partisanen gelangten in den Einheiten zu Informationen, indem sie die zugeschickten Unterlagen und Fotografien analysierten. ${ }^{2}$

Für bestimmte Personengruppen war es in Gebieten unter der Besatzung der deutschen Wehrmacht und der Ustascha strengstens verboten, Fotoapparate zu besitzen. Jene Teile der Bevölkerung, die unter die Rassengesetze fielen, mussten den Besitz sogar mit ihrem Leben bezahlen. Unmittelbar nach der Gründung des Unabhängigen Staates Kroatien wurden in den Häusern der Juden und Serben außer Fotoapparaten auch Radioempfänger und Ferngläser beschlagnahmt. ${ }^{3}$ In Zadar requirierte man in einzelnen Häusern von Familien sogar Schreibmaschinen, ${ }^{4}$ während in den anderen Teilen des Staates allen Juden befohlen wurde, ihre Fahrräder und Autos den Regierungsbehörden zu übergeben. ${ }^{5}$ Der Handel mit fotografischen Chemikalien unterstand der Aufsicht der Behörden, die von jedem Händler verlangten, besondere Verzeichnisse über die eigenen Kunden und über diejenigen, die diese Chemikalien kauften, zu führen. Der Belgrader Fotograf Branko Savić erinnert sich:

»Ich reiste drei Mal während der Zeit des Unabhängigen Staates Kroatien zu den Ustascha nach Zagreb, um Fotomaterial zu besorgen, nachdem dieses in Belgrad nicht zu bekommen war. Mit gefälschten Passierscheinen oder ohne sie. Jedes Mal durchsuchte die Polizei den ıfalschen Koffer. Immer jenen mit meinen persönlichen Sachen und nicht mit dem geschmuggelten Mate-

\footnotetext{
1 Zbornik dokumenata i podataka o narodno-oslobodilačkom ratu jugoslovenskih naroda. Bd. II/6: Dokumenta vrhovnog štaba Narodnooslobodilačke vojske Jugoslavije 1942. Belgrad 1957.

2 Zbornik dokumenata i podataka o narodno-oslobodilačkom ratu jugoslovenskih naroda. Bd. II/10: Dokumenta vrhovnog štaba Narodnooslobodilačke vojske Jugoslavije 1943. Belgrad 1962.

3 Lukač, Dušan. Ustanak u Bosanskoj krajini. Belgrad: VIZ Belgrad 1967, S. 56-57.

4 Zbornik dokumenata i podataka o narodno-oslobodilačkom ratu jugoslovenskih naroda. Bd. IX/3: Partijsko-politička dokumenta 1943. godine. Belgrad 1967.

5 Građa za povijest narodnooslobodilačke borbe u sjeverozapadnoj Hrvatskoj 1941.-1945. Bd. I. Zagreb 1981.
} 
rial. Einmal ging ich nach der polizeilichen Kontrolle zurück zu meiner Bekannten in den Wartesaal. Sie sagte mir: ১Branko, du bist ja blass wie der Todk. Ihm hatte ich ja auch ins Gesicht geschaut. $\ll^{6}$

Als wohl am schwierigsten erwies sich die streng konspirative Tätigkeit für jene Fotografen, die Mitglieder der Widerstandsbewegung außerhalb der befreiten Gebiete waren. Ihre Aufgabe bestand vor allem in der Erstellung gefälschter Ausweise, ${ }^{7}$ die man benötigte, um sich auch außerhalb der Städte frei bewegen und in die befreiten Gebiete reisen zu können. Falls sie »aufflogen«, durfte keine einzige Fotografie in die Hände des Feindes gelangen. Den Untergrundkämpfern war strengstens untersagt, Fotografien anderer Mitglieder der Widerstandbewegung bei sich zu tragen, was auch aus dem Brief von Koloman Barany, Mitglied des Kreiskomitees der kommunistischen Partei Kroatiens für Varaždin, vom 24. Juni 1942 hervorgeht. Darin ist zu lesen, dass man sich durchaus bewusst war, welche Gefahr solche Fotografien für das illegale Netzwerk der Partisanen bedeuten konnten. ${ }^{8}$ In Zagreb arbeitete das Ortskomitee der Kommunistischen Partei einen Plan für die Schleusung von Personen zu den Partisaneneinheiten aus, der von insgesamt fünf Gebietskomitees umgesetzt wurde. Eines dieser Komitees war für den Eisenbahntransport zuständig und verfügte über eine separate Gruppe, die man mit dem Transport der Personen und unterschied-

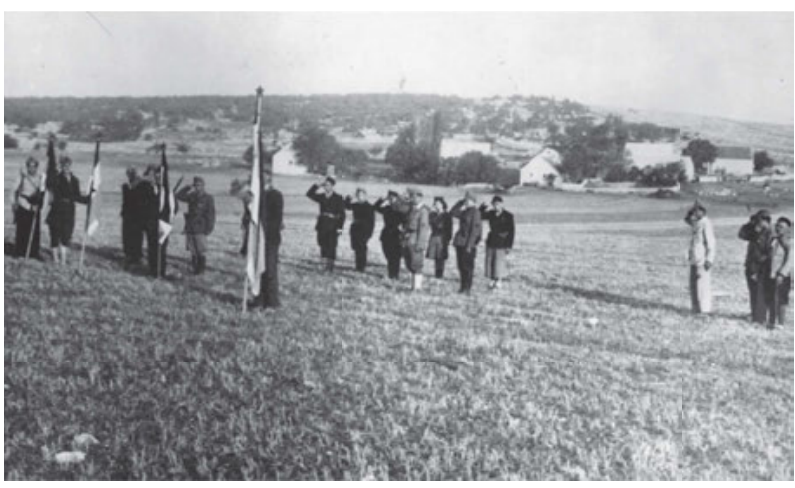

Vereidigung der Ersten Dalmatinischen Brigade im Livanjski-Tal, Kroatien. Belgrad, Militärarchiv | K82 F3 16.

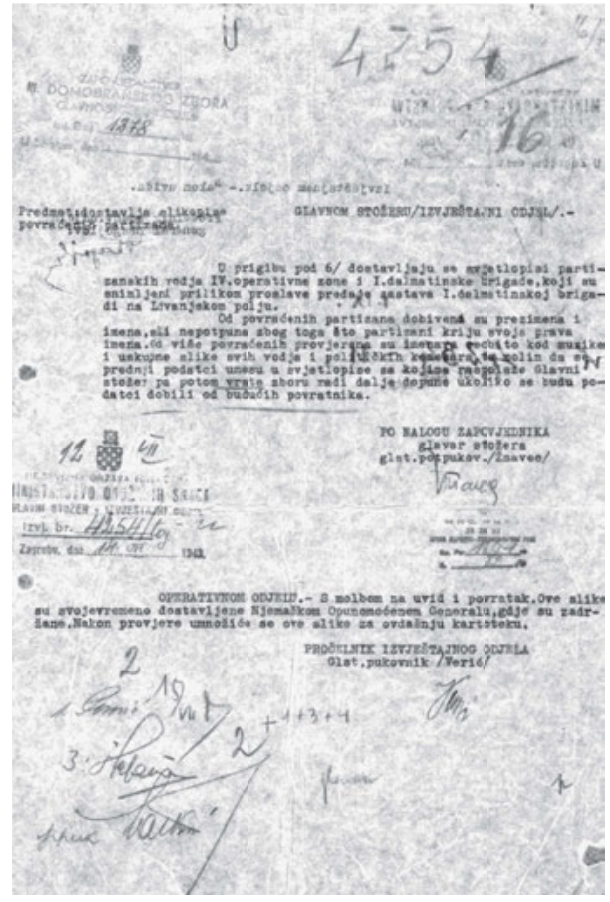

Auflistung der Partisanen vor der Vereidigung der Ersten Dalmatinischen Brigade im Livanjski-Tal, Kroatien. Belgrad, Militärarchiv | K82 F3 16.

6 Rovčanin, Snežana. Kvadrati filma spojili i most. In: Novosti, 07.05.2007. Siehe http://www.novosti.rs/vesti/naslovna/reportaze/aktuelno.293.html:197712-Kvadrati-filma-spojili-i-most [Aufruf am 07.02.2021]. 7 Veber, Norbert. Delatnost u okupiranom Zagrebu. In: Tihić, Esad und Kalem, Momčilo (Hrsg.). Veze u NOB: Ratna sećanja 1941.1945. Bd. 4. Belgrad: Vojnoizdavački zavod 1981, S. 54.

8 Građa za povijest narodnooslobodilačke borbe u sjeverozapadnoj Hrvatskoj 1941.-1945. Bd. II. Zagreb 1981. 


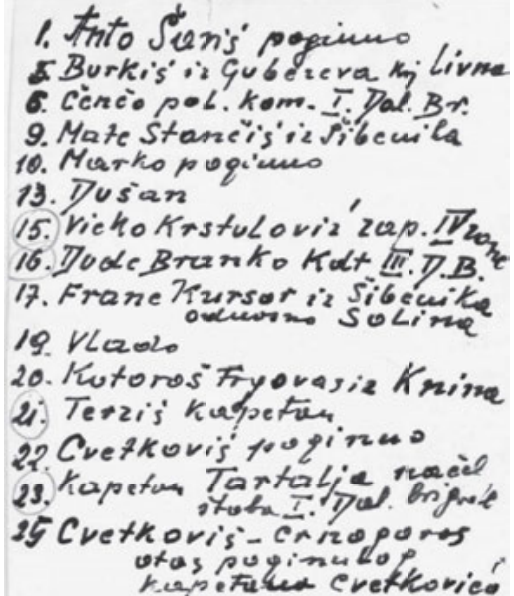

Auflistung der Partisanen vor der Vereidigung der Ersten Dalmatinischen Brigade im LivanjskiTal, Kroatien. Belgrad, Militärarchiv | K82 F3 16.

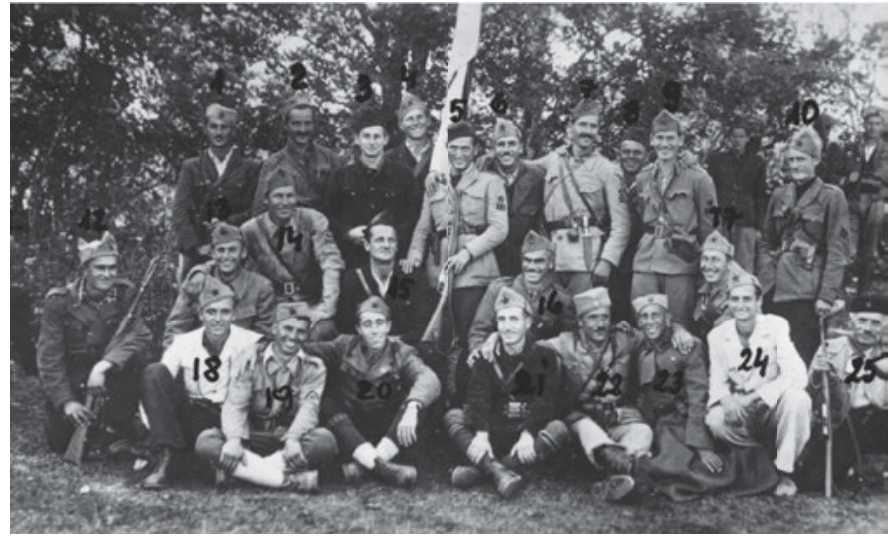

Vereidigung der Ersten Dalmatinischen Brigade im Livanjski-Tal, Kroatien. Belgrad, Militärarchiv | K82 F3 16.

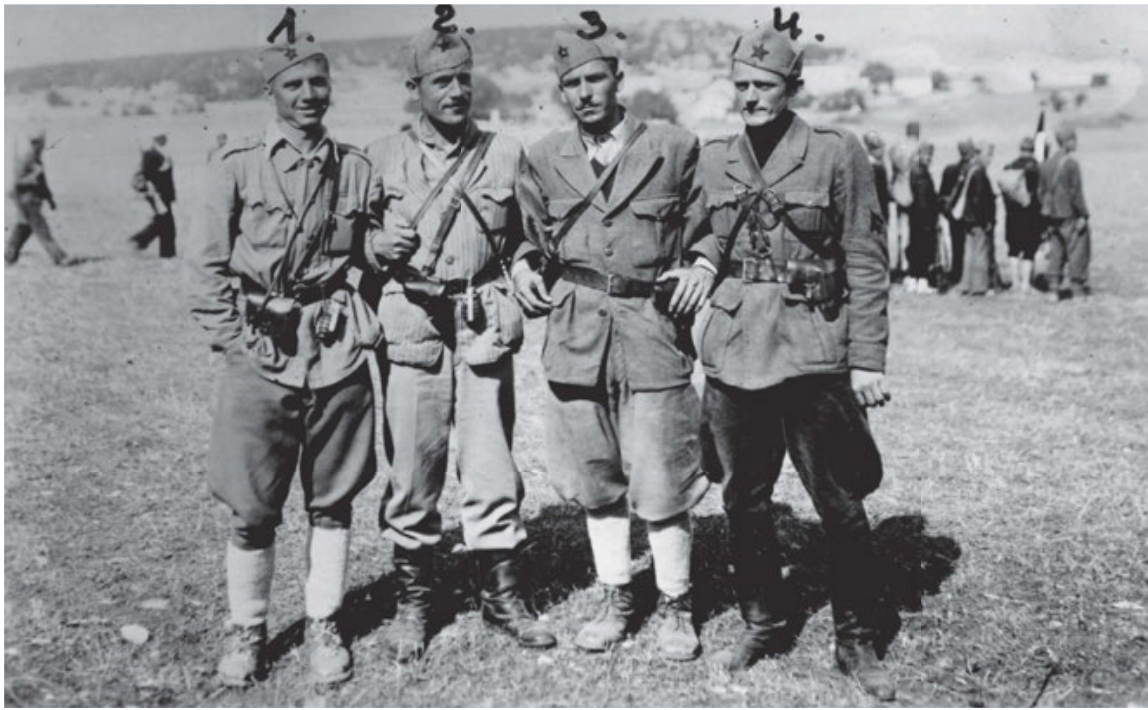

Vereidigung der Ersten Dalmatinischen Brigade im Livanjski-Tal, Kroatien. Belgrad, Militärarchiv | K82 F3 16.

1..

2.- Cretkovis Kult. Eriguale - pooicuno 3. "Cencio" pol. Komesor I. Dalm. brigade 4. - "Marko" Kalt. I. Dalm. brigg a de. pugimo 
lichen Materialien in die befreiten Gebiete betraute. Allein im ersten Kriegsjahr haben sich circa 25.000 Einwohner der Stadt Zagreb, deren gefälschte Ausweise mit der Hand angefertigt wurden, den Partisanen angeschlossen. ${ }^{9}$

Die erste Zagreber Kriegstechnik zur Erstellung gefälschter Ausweise befand sich in der Wohnung von Dragutin Susović in der Derenčinova-Straße 21d, in der neben dem Wohnungseigentümer auch Maks Durjava tätig war, der fotografisches Material besorgte. ${ }^{10} \mathrm{Zu}$ Sitzungen des Ortskomitees traf man sich oft in der Wohnung des Fotografen Srećko Delhunija in der Ilica-Straße $124 .{ }^{11}$ Da es nahezu unmöglich war, fotografisches Material unbemerkt zu beschaffen, nutzte man für die Besorgung die bereits existierenden Verbindungen zu den Beschäftigten im Fotoladen Corsa und der Vertretung von Agfa-Gevaert in der Ilica. ${ }^{12}$ Als man keine unausgefüllten Vordrucke für Ausweise mehr beschaffen konnte, wurde dazu übergegangen, die Tinte zu löschen und falsche Namen einzutragen. ${ }^{13}$ Nach der Entwicklung der Fotografien vernichtete man alle Negative. Die Untergrundkämpfer in Zagreb waren auch damit beauftragt, angesehene Persönlichkeiten der Ustascha heimlich zu fotografieren und anschließend die Aufnahmen in die befreiten Gebiete zu schicken, was mit der Zeit ebenso in anderen kroatischen Städten praktiziert wurde. Auf diese Weise legte man ein Archiv an, mit dessen Hilfe potenziell eingeschleuste Agenten in den Reihen der Partisanen oder deren mögliche Handlanger innerhalb der Partisanenbewegung identifiziert werden konnten.

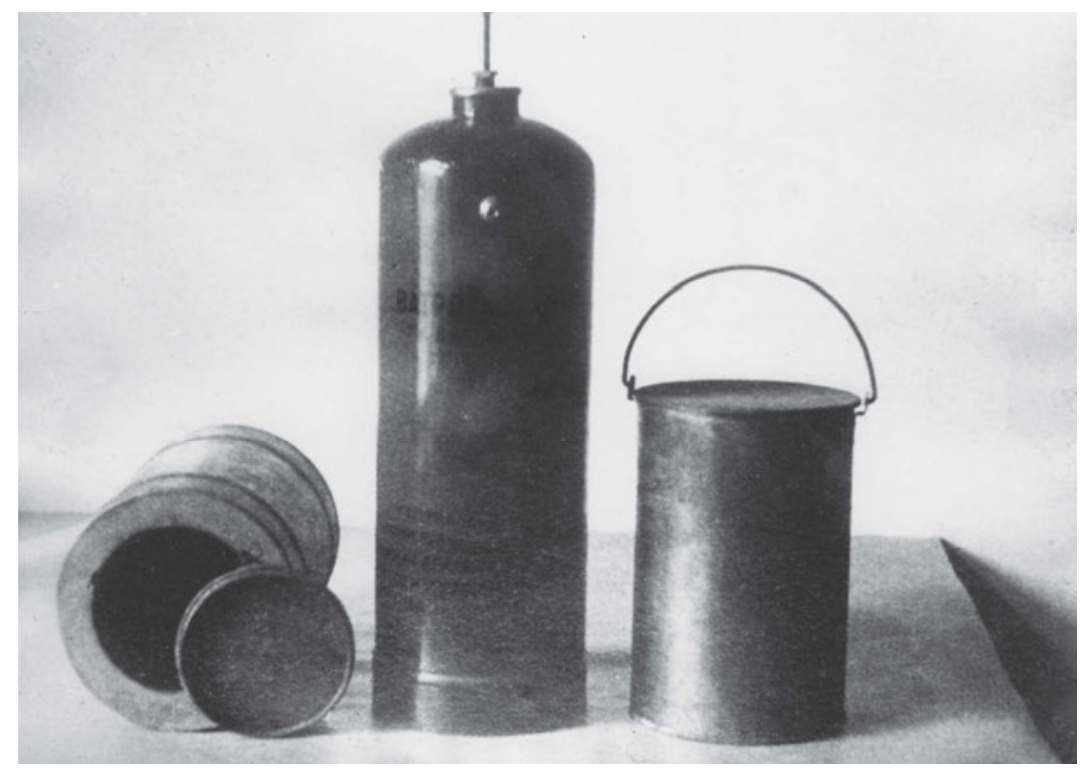

Speziell angefertigte Gegenstände zum Schmuggeln von Post und Literatur. Fotograf unbekannt. Ljubljana, Museum der Volksbefreiung Sloweniens | 10902/znaci.net.

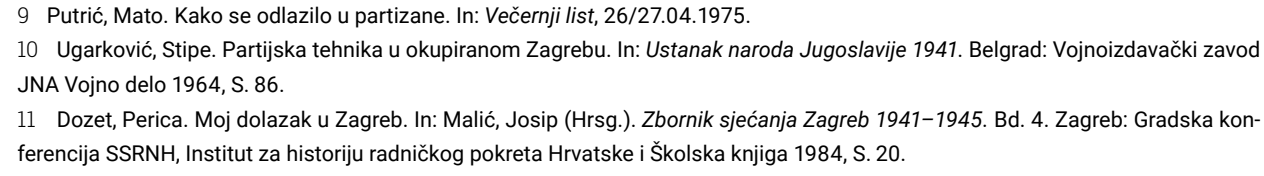




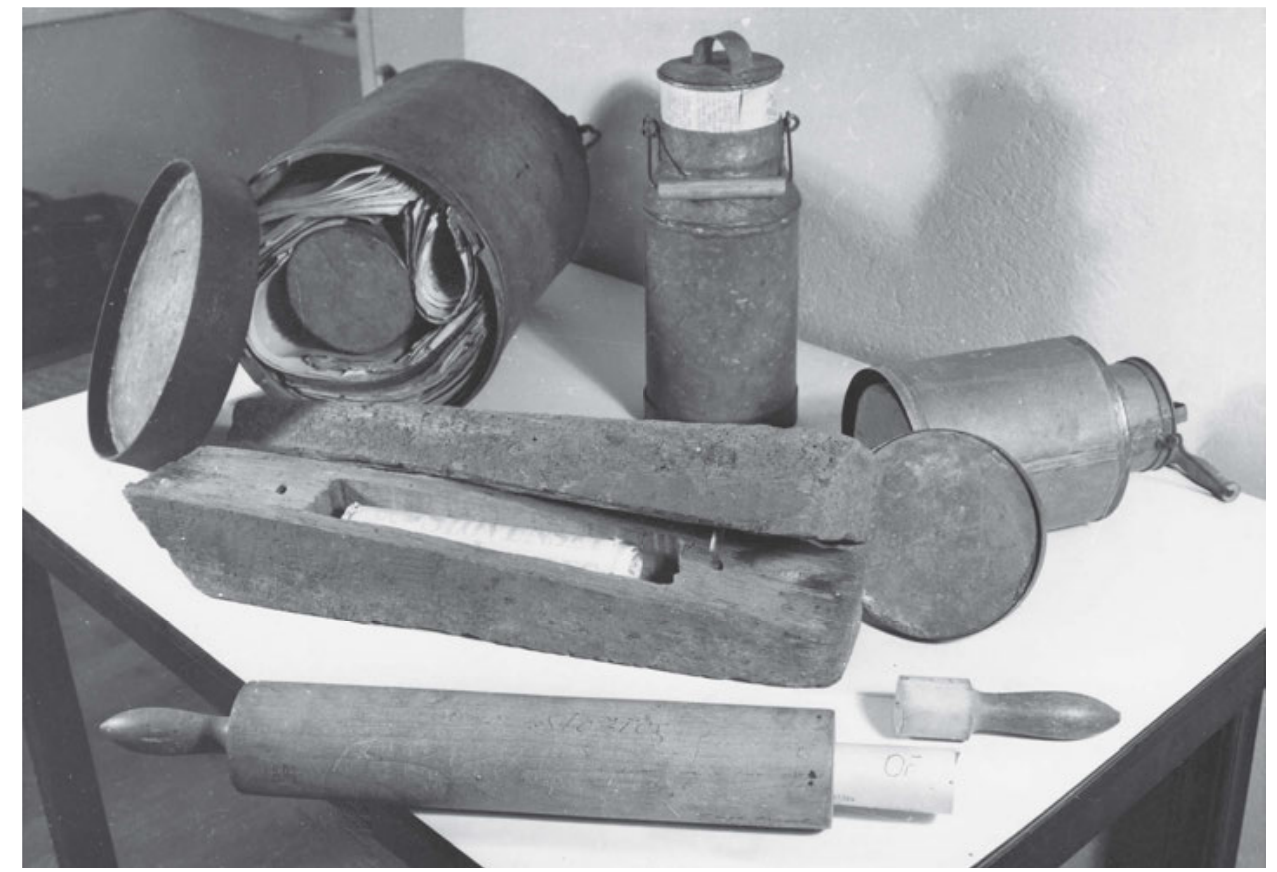

Speziell angefertigte Gegenstände zum Schmuggeln von Post und Literatur. Fotograf unbekannt. Ljubljana, Museum der Volksbefreiung Sloweniens | 10903/znaci.net.

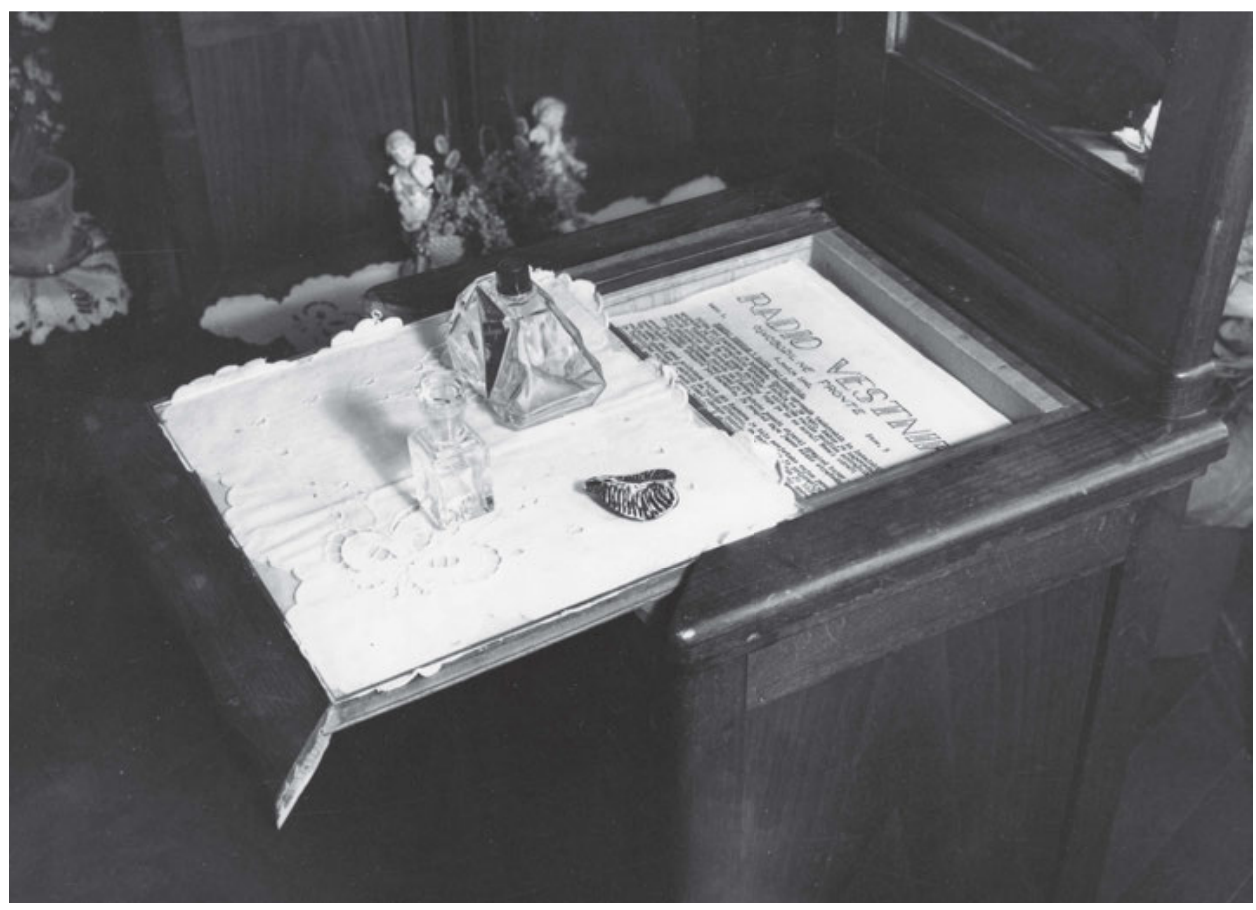

Speziell angefertigte Gegenstände zum Schmuggeln von Post und Literatur. Fotograf unbekannt. Ljubljana, Museum der Volksbefreiung Sloweniens | 10904/znaci.net. 
Auf der anderen Seite waren die feindlichen nachrichtendienstlichen Aktivitäten gut organisiert und in voller Entfaltung. Das Oberkommando der Abwehr in Zagreb erstellte am 22. Februar 1942 ein Album der Partei- und Partisanenführer, ${ }_{1}^{14}$ während die Polizei gleichzeitig vergrößerte Aufnahmen von Personen anfertigte, von denen man annahm, sie würden der antifaschistischen Widerstandsbewegung angehören. Die Abzüge verteilte man zusammen mit den gesammelten Informationen über potenziell verdächtige Mitglieder der Widerstandsbewegung an das Netzwerk der Agenten in Zivilkleidung auf den Straßen, die ohne Warnung auf jeden Verdächtigen schießen durften..$^{15}$

In Rijeka spielte sich zu Beginn des Krieges ein wahrer Action-Thriller ab. Für die Gestapo arbeitete damals der aus Sušak stammende Fotograf Karlo Lau Ritz, gebürtig aus Bela Crkva in der Vojvodina, der zugleich Besitzer des Fotoladens Desa war und bereits vor dem Ausbruch des Zweiten Weltkrieges Verbindung zum deutschen militärischen Geheimdienst aufgenommen hatte. Seine häufigen Reisen nach Deutschland rechtfertigte er mit der eigenen beruflichen Weiterbildung und dem Besuch von Fotokursen. Im Zweiten Weltkrieg dehnte er seine Tätigkeit auf die Verhaftung und Verhöre gefangener Widerstandskämpfer aus. ${ }^{16}$ Auf der anderen Seite arbeitete ein Angestellter aus der polizeilichen Kartothek für die Widerstandsbewegung in Rijeka, der jeweils montags und freitags der Widerstandsbewegung etwa zwei Dutzend vertraulicher Karteikarten mit den Namen polizeilicher Agenten und ihrer Mitarbeiter zukommen ließ. Der Fotograf Simo Milković machte im Friseurladen von Živko Jović heimlich Aufnahmen von diesen Unterlagen, um die Abzüge später nach Kostren zu schicken, wo sie Partisanenkuriere in Empfang nahmen und auf das befreite Territorium brachten. ${ }^{17}$

Nachrichtendienstliches und propagandistisches Material gelangte aber auch in umgekehrter Richtung aus den befreiten Gebieten in die Städte. Fotografien, die Kriegserfolge und Siege der Partisanen zeigten, wurden in den besetzten Gebieten verteilt und lösten beim Feind erhebliche Beunruhigung aus. Zumeist wählte man jene Fotografien aus, denen der größte Propagandaeffekt zugeschrieben wurde, ${ }^{18}$ aber auch solche, bei denen man annahm, sie könnten neue Sympathisanten und Soldaten anziehen. ${ }^{19}$

Während der Okkupation wirkte die Jugendorganisation der Kommunistischen Partei Jugoslawiens in den Mittelschulen von Zagreb und versammelte etwa vierzig junge Mädchen und circa hundert Sympathisantinnen. Um keinen Verdacht zu erwecken, hielten sie

\footnotetext{
12 Susović, Dragutin. U partijskoj tehnici. In: Malić, Josip (Hrsg.). Zbornik sjećanja Zagreb 1941-1945. Bd. 3. Zagreb: Gradska konferencija SSRNH, Institut za historiju radničkog pokreta Hrvatske i Školska knjiga 1984, S. 223.

13 Čobanski, Mila, Golubović, Zvonimir und Kumanov, Živan. Novi Sad u ratu i revoluciji 1941-1945. Novi Sad: Institut za izučavanje Vojvodine 1976, S. 419.

14 Nemačka obaveštajna služba [Deutscher militärischer Geheimdienst], IX.

15 Perović, Lepa. Ilegalni partijski rad u Zagrebu. In: Malić, Josip (Hrsg.). Zbornik sjećanja Zagreb 1941-1945. Bd. 4. Zagreb: Gradska konferencija SSRNH, Institut za historiju radničkog pokreta Hrvatske i Školska knjiga 1984, S. 11.

16 Butorović, Radule. Sušak i Rijeka u NOB. Rijeka: Centar za historiju radničkog pokreta i NOR Istre, Hrvatskog primorja i Gorskog Kotara 1975, S. 341.

17 Ebd., S. 429.

18 Zbornik dokumenata i podataka o narodno-oslobodilačkom ratu jugoslovenskih naroda. Bd. V/4: Borbe u Hrvatskoj 1942. godine. Belgrad 1954.

19 Zbornik dokumenata i podataka o narodno-oslobodilačkom ratu jugoslovenskih naroda. Bd. V/30: Borbe u Hrvatskoj $1941 .-1942$. godine. Belgrad 1963
} 
ihre Sitzungen sonntags nach der Messe ab und organisierten Ausflüge, Lesegruppen, gemeinsame Kinobesuche und Teilnahmen an wissenschaftlichen Vorträgen der Volkshochschule, denen Debatten über die Vorträge folgten. Doch im Unterschied zu anderen Jugendorganisationen der Kommunistischen Partei Jugoslawiens hatten diese jungen Mädchen auch eine Fotoamateurgruppe gegründet. ${ }^{20}$ Die Schülerin des Ersten Mädchengymnasiums Zorka Fak war mit der illegalen Distribution der Fotografien betraut, auf denen die Verbrechen der Ustascha zu sehen waren:

"Es ist heute schwer zu sagen, auf welchem Wege Ende [sic!] 1941 die Aufnahmen der grausamen Folterungen der Kommunisten, Juden und Serben in den Lagern der Ustascha nach Zagreb gelangt sind. Dies waren schreckliche Zeugnisse der von den Besatzungsmächten und ihren einheimischen Vasallen begangenen Verbrechen. Es galt, sie zu vervielfältigen und in der Stadt zu verteilen. Eines Tages kam die Genossin Zorka Fak (aus dem Ersten Mädchengymnasium) und erteilte unserem Gymnasium den Auftrag, dieses Problem zu lösen. Das Bad in der Wohnung einer der Schülerinnen in der Deželićeva-Straße 60 wurde in ein kleines Fotolabor verwandelt. Einige Tage später brachten zwei Mädchen aus der Jugendorganisation kleine Pakete mit einigen Hundert Fotografien zum >Verbindungsmann.$^{21}$

Zur selben Zeit existierte in Dalmatien ebenfalls eine starke Widerstandsbewegung, der auch viele Partisanenfotografen angehörten, beispielsweise der aus Split stammende Fotograf Marcel Njegovan aus der Plinarska-Straße 14, den die italienischen Besatzungsmächte am 18. Juni 1942 wegen des Beschmierens der italienischen Straßennamen mit schwarzer

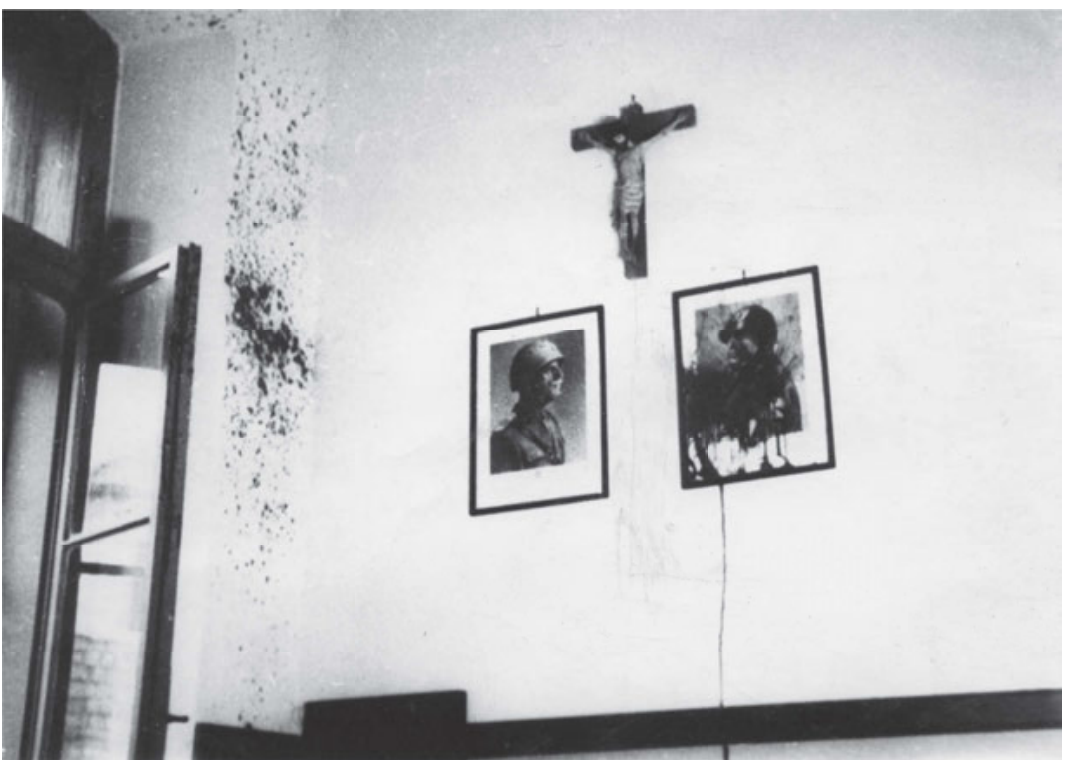

Kruzifix und beschmierte Fotografien der italienischen Besatzung (das rechte Porträt zeigt Benito Mussolini) in Split, Kroatien. Fotograf unbekannt. Zagreb, Kroatisches Historisches Museum | HPM/MRNH-R-5740.

20 Škrinjar, Sonja. Djevojke iz treće ženske. In: Tihić, Esad (Hrsg.). Revolucionarni omladinski pokret u Zagrebu 1941.-1945. Bd. II. Zagreb: Gradska konferencija SSRNH, Gradski odbor Saveza udruženja boraca NOR-a, Sveučilišna naklada Liber 1984, S. 150. 21 Pavičić, Sofija-Maša und Fak-Horvatić, Zorka. Borbena Prva ženska gimnazija. In: Tihić, Esad (Hrsg.). Revolucionarni omladinski pokret u Zagrebu 1941.-1945. Bd. II. Zagreb: Gradska konferencija SSRNH, Gradski odbor Saveza udruženja boraca NOR-a, Sveučilišna naklada Liber 1984, S. 147. 
Farbe verhaftet hatten. ${ }^{22}$ Das faschistische Blatt /l popolo di Spalato veröffentlichte regelmäßig Informationen über diese ersten Aktionen gegen die italienischen Besatzer. Im Gegensatz zu den deutschen Besatzern verteilten die italienischen Streitkräfte selbst Fotografien öffentlicher Hinrichtungen, sich wohl dessen nicht bewusst, dass diese Aufnahmen die lokale Bevölkerung zu noch stärkerem Widerstand bewegen könnten. Solche Fotografien stellten für die Partisanen wichtiges Propagandamaterial dar. In den Besitz einer ganzen Sammlung entsprechender Fotografien gelangte auch Vicko Krstulović. Im Ort Donji Lapac, in dem die damalige Redaktion der Zeitung Vjesnik ihren Sitz hatte, übergab er am 26. August 1941 Otmar Kreačić-Kultura und Vjera Jurić Fotos, auf denen die Erschießung der Angehörigen der Partisaneneinheit aus Split dokumentiert war. ${ }^{23}$

In Sarajevo waren Fotoausstellungen bereits in den Jahren vor Kriegsausbruch Zielscheibe der kommunistischen Jugendbewegung. Einer der bekanntesten Angriffe spielte sich im Frühling 1938 ab, als eine Gruppe junger Männer unter Anführung von Vasa Miskin die Eröffnung einer Fotoausstellung der Serbischen Radikalen Partei zu verhindern beschloss. Den Parteivorsitz hatte Milan Stojadinović, der gleichzeitig auch Ministerpräsident der Regierung des Königreichs Jugoslawien war und vom nationalsozialistischen Deutschland tatkräftig unterstützt wurde. Den Jugendlichen gelang es, einen Großteil der Fotografien zu entwenden und dann auf der Straße vor dem Rathaus öffentlich in Stücke zu reißen. ${ }^{24}$

Zu Beginn des Krieges stand Sarajevo unter der Besatzung der Ustascha. Der Hauptkommandant Ivan Zorko gab am 23. Juni 1941 den Befehl, allen Juden und Serben Fotoapparate und Rundfunkempfänger wegzunehmen, alle kyrillischen Aufschriften zu tilgen sowie in Geschäften der Juden und Serben Beauftragte der Ustascha einzusetzen. Entwendet wurden des Weiteren Motorfahrzeuge, Schreibmaschinen, Fahrräder und alle Wertgegenstände..$^{25}$ Doch zur selben Zeit tauchten in der Stadt Partisanenfotografien und Plakate auf, die im Schutz der Dunkelheit vor allem Mitglieder der Kommunistischen Jugend verteilten und auf Wände klebten. Unter ihnen befanden sich Stevo Nevjestić, der als Fotograf in der Gespanschaftspolizei arbeitete, sowie Ivica Lisac, der für die illegale Vervielfältigung der Fotografien zuständig war. ${ }^{26}$

»Plötzlich wurden, wie dies in solchen Situationen stets üblich war, Sitzungen der Kommunistischen Jugend organisiert, man teilte die Leute in Gruppen ein, verteilte Materialien, beauftragte die Sekretäre, zusammen mit den Mitgliedern ihres Aktivs die Aktion nachts schnell, gleichzeitig und ohne Verluste durchzuführen. Die Bewohner der Stadt Sarajevo fanden die Fotografien in ihren Postfächern, auf ihren Treppen, unter den Fenstern, in den Höfen, an gut einsehbaren und stark befahrenen Plätzen, in Fabriken. « ${ }^{27}$

\footnotetext{
22 Arhiv VII K 533, Reg.-Nr. 38/8-1.

23 Krstulović, Vicko. Memoari jugoslavenskog revolucionara I. Sarajevo: Buybook 2012, S. 287.

24 Radić, Josif. Borba omladine željezničke zanatske škole. In: Malić, Hrvoje (Hrsg.). Sarajevo u revoluciji. U borbi do punog oslobođenja (novembar 1943-april 1945.). Sarajevo: Oslobođenje 1981, S. 366.

25 Arhiv VII, NDH [Unabhängiger Staat Kroatien], Schachtel 171, Reg.-Nr. 2/18-1.

26 Mikulić, Mario. Plakati i Titove slike širom okupiranog Sarajeva. In: Malić, Hrvoje (Hrsg.). Sarajevo u revoluciji. U borbi do punog oslobođenja (novembar 1943-april 1945.). Sarajevo: Oslobođenje 1981, S. 232.

27 Ebd., S. 233.
} 
Für die Erhebung nachrichtendienstlich relevanter Informationen in Sarajevo waren die Tätigkeiten des Hauptmanns der Landwehr, Muhamed Šefkić, und des Oberstleutnants Šefket Hasandedić besonders wichtig. Heimlich fotografierten sie militärische Pläne und Skizzen, um dieses äußerst wertvolle nachrichtendienstliche Material dann über Kuriere dem Stab der Zehnten Division zukommen zu lassen. ${ }^{28}$ Šefkić und Hasandedić waren auch für die Versorgung der Partisaneneinheiten mit fotografischem Material und Fotoapparaten sowie für die Anfertigung gefälschter Ausweispapiere zuständig. Das gesamte Material übergaben sie unbemerkt, jedoch vor den Augen des Feindes im Lager des Fotoateliers Karahasanović, das sich gegenüber dem Büro der Gestapo im Hotel Gaza in Sarajevo befand. Abgesehen von ihnen war das Atelier Foto Enis mit der Fälschung von Ausweisen betraut. In den Frühlingsmonaten entstand in Sarajevo ein einzigartiges Fotoarchiv der Partisanen, in dem sich 4.000 Karteikarten mit Angaben zu Personen befanden, die man der Kriegsverbrechen verdächtigte..$^{29}$

Besonders erwähnenswert als einer der bereits vor dem Krieg bedeutenden Fotografen ist Milan Pavić, Korrespondent der Zeitung Politika. Bei Kriegsausbruch lebte und arbeitete Pavić in Daruvar, doch als Sympathisant der Partisanenbewegung war er für den Transport von Personen auf das befreite Territorium und die Anfertigung gefälschter Ausweise zuständig. Seine Gruppe flog jedoch sehr schnell auf. Nach der Verhaftung und einiger Zeit im Gefängnis gelang es Pavić, wieder freizukommen. Kurz darauf begann er, für den Filmdienst des Unabhängigen Staates Kroatien in Zagreb zu arbeiten. Sein eigenes Leben riskierend, setzte er während des gesamten Krieges seine Zusammenarbeit mit der antifaschistischen Bewegung fort, indem er in erster Linie nachrichtendienstliche Tätigkeiten verrichtete, die Partisanen aber auch erfolgreich mit Fotomaterial, vor allem Chemikalien und Fotopapier, sowie Medikamenten versorgte. ${ }^{30}$

Mitte 1944 wurde Pavić Berichterstatter der Partisanenpresse in Zagreb. Informationen, die von den höchsten Stellen kamen, sammelte er heimlich, anfangs einmal, später zweimal und schließlich dreimal wöchentlich, und chiffrierte das Material. Seine Berichte verfasste er in seiner Wohnung in der Buconjićeva-Straße 6/1, als würde er aus den befreiten Gebieten und nicht aus dem Stadtzentrum von Zagreb berichten. Die geordneten Berichte übergab er heimlich seinem Mittelsmann, dem Ingenieur Machaček in der Istarska-Straße 17, der sie an die in der Nähe der Remise wohnende Radiotelegrafistin Ljerka Dulčić weiterleitete. ${ }^{31}$ Zusammen mit Machalček und Bischof Bukatka fertigte er im April 1945 für die Soldaten und Flieger der Alliierten heimlich Fotos des Konzentrationslagers Jasenovac, damit die Alliierten den genauen Standort wussten und ihre Flugzeuge keine Bomben auf

28 Ebd., S. 266.

29 Grbac, Zvonko. O vojnoobavještajnom radu za NOP u neprijateljskim vojnim i drugim institucijama. In: Albahari, Nisim et al. (Hrsg.). Sarajevo u revoluciji. U borbi do punog oslobođenja (novembar 1943.-april 1945. Sarajevo: Istorijski arhiv Sarajevo 1976, S. 619.

30 Pavić, Milan. Kamera je zabilježila posljednje događaje u Zagrebu. In: Malić, Josip (Hrsg.). Zbornik sjećanja Zagreb. Zagreb: Gradska konferencija SSRNH Zagreb, Institut za historiju radničkog pokreta Hrvatske 1984. S. 394.

31 Ebd., S. 395. 
das Lager abwarfen. Pavić war für die Abschrift des Memorandums der Ustascha verantwortlich, das er an die westlichen Alliierten geschickt hatte, um sie darin um Schutz vor den Briten zu ersuchen. ${ }^{32}$

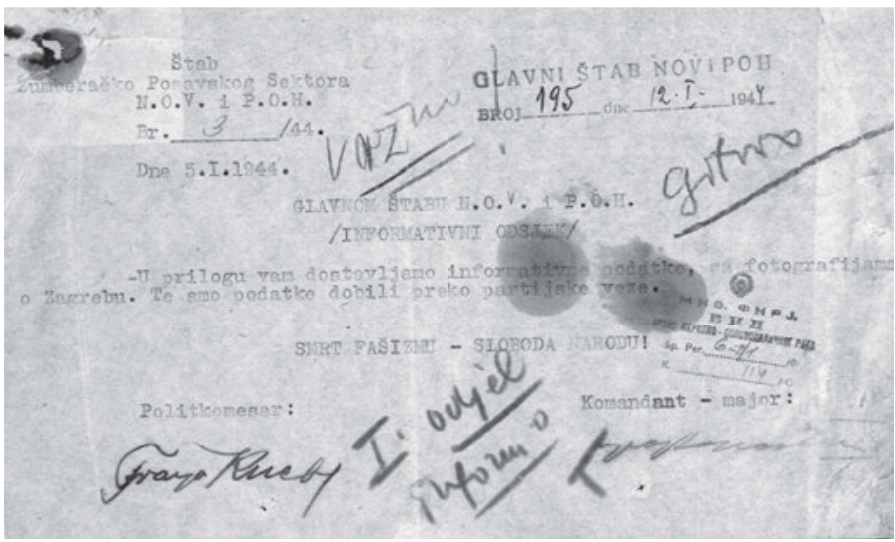

Informationen zu Fotografien aus Zagreb. Belgrad, Militärarchiv | K114 F1 6.

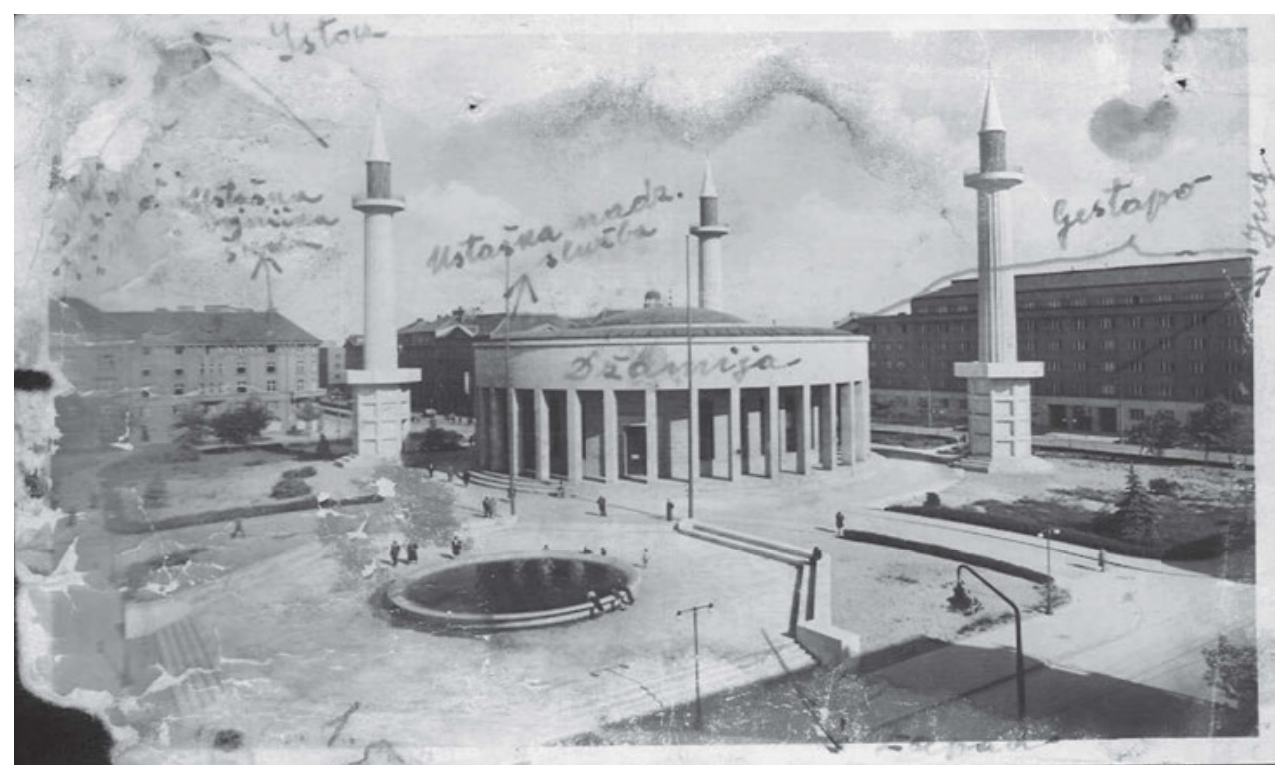

Informationen zu Fotografien aus Zagreb (Moschee). Belgrad, Militärarchiv | K114 F1 6. 


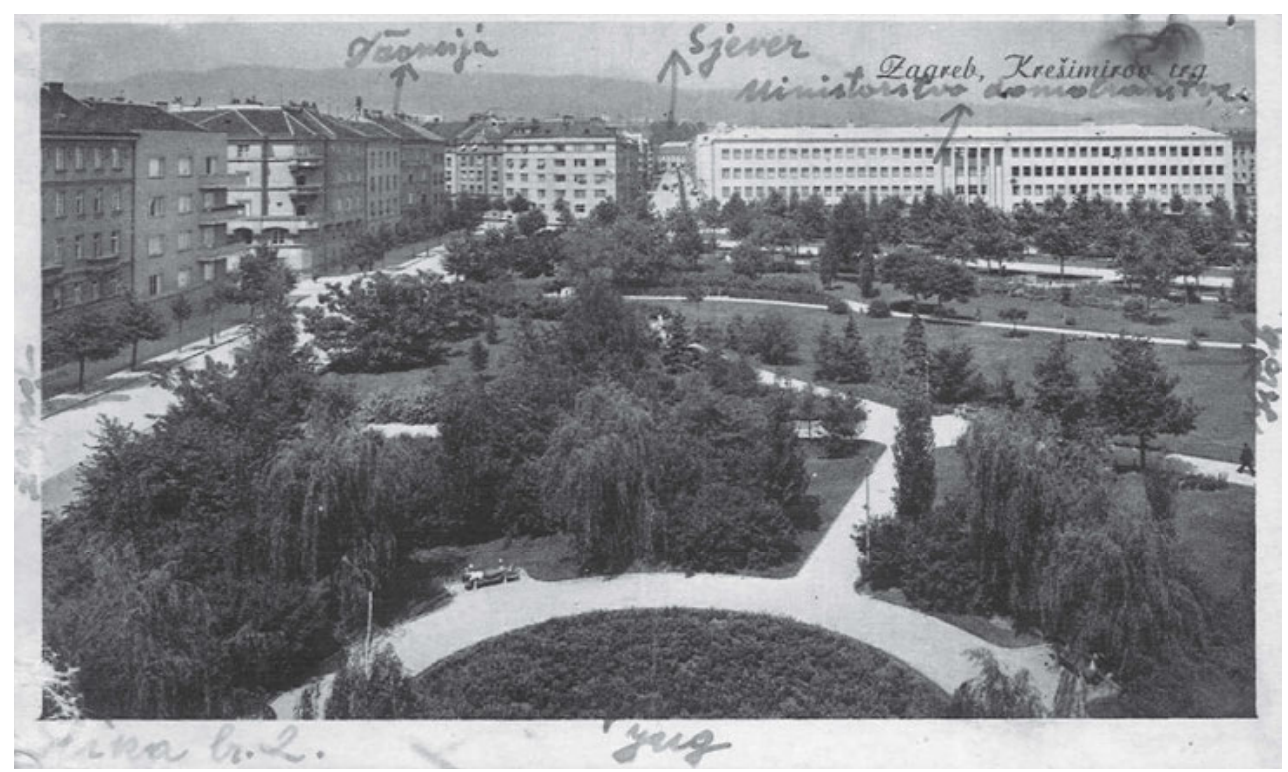

Informationen zu Fotografien aus Zagreb (Krešimir Platz). Belgrad, Militärarchiv | K114 F1 6.

Pavićs Plan, Zagreb zu verlassen und sich zusammen mit einer größeren Gruppe von Antifaschisten dem Antifaschistischen Landesrat der Volksbefreiung Kroatiens anzuschließen, wurde von den Ustascha jedoch aufgedeckt und seine Reise auf das befreite Territorium auf diese Weise vereitelt. Pavić blieb in Zagreb und erhielt von den Behörden der Ustascha Anfang 1945 den Auftrag, die Reise der Ustascha-Garde nach Novska und Jasenovac fotografisch zu dokumentieren, während die Partisanen ihm gleichzeitig zur Aufgabe machten, das Lager heimlich zu fotografieren. ${ }^{33}$

"Luburić verbot uns zu fotografieren, sagte jedoch, dass wir, wenn wir etwas sehen, was man zu Propagandazwecken nutzen konnte, für jede Aufnahme seine oder die Genehmigung seines Stellvertreters, Oberst Džala, einholen müssten und widrigenfalls für immer im Lager bleiben könnten. Vom (18 $\mathrm{m}$ hohen) Aufsichtsturm am Eingang des Lagers aus machte ich mit Džalas Zustimmung eine Panoramaaufnahme des gesamten Lagers $(3$ Negative $6 \times 6 \mathrm{~cm}$ ). An jenem Tag verlieh der Großgespan Servaci Maks Luburić einen Orden anlässlich des vierten Jahrestags der Aufsicht durch die Ustascha. Luburić zeichnete seine Stellvertreter und Henker aus, darunter Oberst Pavlović, Džala und andere. Ich nutzte diese Gelegenheit, um Luburić (dessen Bild bis dahin in der Presse niemals veröffentlicht wurde), aber auch der Reihe nach all seine Handlanger bei der Ermordung der Menschen zu porträtieren. Nach der Rückkehr fertigte ich in Zagreb davon Abzüge im Format $13 \times 18 \mathrm{~cm}$ zusammen mit den Fotografien des ganzen Lagers an (Montage von 3 Aufnahmen) und übergab sie dem übergeordneten Mittelsmann (Duško Doder), der sie in das befreite Territorium weiterleitete. Alle Aufnahmen (Negative) wurden im Fotoarchiv der Propagandaabteilung hinterlegt, während die vom Wachturm aus gefertigten Fotografien in das sogenannte Geheimarchiv gelangten. ${ }^{34}$ 
Wie im Falle von Branko Savić handelt es sich um Fotografien des Lagers Jasenovac, die bis heute nicht gefunden wurden. Jener Teil des Archivs über die Ustascha, den Pavić retten konnte, gelangte in die Agentur für Fotodokumentationen, doch ist das Schicksal dieser Fotografien unbekannt geblieben. Kurz vor Kriegsende sollte Pavić einen Fotodienst in Zagreb organisieren, der imstande sein würde, eine große Zahl an Fotografien für die Presse und zu unterschiedlichen Propagandazwecken bereitzustellen.

"Acht Tage vor der Befreiung erhielt ich durch den mir übergeordneten Mittelsmann den Auftrag, einen illegalen Kontakt zum Fotografen Tošo Dabac aufzunehmen, der ein Fotoatelier und Fotolabor in der Ilica-Straße 71/1 besaß, und inn zu fragen, ob er gewillt sei, sein Atelier und sein Labor nach der Befreiung zu Zwecken der Fotopropaganda zur Verfügung zu stellen, sollte das Gebäude der Propagandaabteilung gesprengt werden, was allem Anschein nach durchaus möglich war. Ich sprach Dabac als Fotofreund und Bekannten am heutigen Platz der Brüderlichkeit und Einheit (Blumenplatz) an und setzte inn über die Anfrage der Volksbefreiungsbewegung in Kenntnis. Er schaute mich anfangs ungläubig und verwundert an, erklärte sich dann aber ohne zu Zögern bereit, sein Atelier und sein Labor bereitzustellen. « ${ }^{35}$

Während des gesamten Krieges war unbefugtes Fotografieren innerhalb und außerhalb der Konzentrationslager strengstens untersagt, bei Verstößen gegen diese Vorschrift drohte die Todesstrafe. ${ }^{36}$ Einzelne Personen setzten sich jedoch bewusst über die Gesetze hinweg, darunter der Eisenbahner Mate Djukić, der das Lager Jasenovac aus der Ferne aufgenommen hatte. Zeugnisse der dortigen Gefangenen besagen, dass Hinko Dominik Piccili, Oberstleutnant der Ustascha und Befehlshaber im Lager Ziegelei III - wo er unter anderem ein primitives Krematorium konstruiert hatte, in dem lebende Insassen verbrannt wurden ${ }^{37}$ oftmals mit seinem Leica-Fotoapparat durch das Lager schritt und Häftlinge fotografierte. ${ }^{38}$ In Belgrad fuhr der Stellvertreter des Kommandanten des Lagers Banjica, Peter Krüger, der für sein unmenschliches und grausames Vorgehen und die Ermordung von Gefangenen bekannt war, mit dem Fahrrad über das Lagergelände und fotografierte die Insassen jedes Mal, wenn ihm etwas verdächtig vorkam. ${ }^{39}$

Aufgrund der Struktur der Untergrundorganisation wussten oftmals nicht einmal ihre Mitglieder selbst, wer zu den Mitgliedern gehörte, weshalb auch Pavić nicht ahnen konnte, dass Tošo Dabac, der sich zunehmend von den Propagandatätigkeiten für das Ustascha-Regime distanzierte, 1943 begonnen hatte, der Partisanenbewegung Fotoausrüstungen und Fotomaterial zu schicken. Er verschenkte seinen Fotoapparat Contax II, einen Belichtungsmesser und Fotomaterial im Wert von damals 20.000 Kuna, weswegen er im Juni 1944 ins Gefängnis kam. ${ }^{40}$ Gegen Ende des Krieges, am 5. April 1945, schickten die Zagreber Untergrundkämpfer Pläne der Ustascha für die Verteidigung Zagrebs in das bereits ins Leben gerufene Verteidigungsministerium, wobei einer dieser Pläne heimlich fotografiert worden war. ${ }^{41}$

35 Ebd., S. 396.

36 Mataušić, Nataša. Koncentracioni logor Jasenovac. Zagreb: Spomen-područje Jasenovac 2008, S. 30.

37 Siehe http://www.jusp-jasenovac.hr/Default.aspx?sid=6248 [Aufruf am 07.02.2021].

38 Mataušić, Nataša. Koncentracioni logor Jasenovac. Zagreb: Spomen-područje Jasenovac 2008, S. 28-29.

39 Begović, Sima. Logor Banjica 1941-1944. Bd. 2. Belgrad: Institut za savremenu istoriju 1989, S. 102.

40 Prosoli, Iva. Monografska obrada umjetničkog opusa Toše Dabca. Bd. 2. Zagreb: Institut za savremenu istoriju 2018,

S. 137-138.

41 Zbornik dokumenata i podataka o narodno-oslobodilačkom ratu jugoslovenskih naroda. Bd. II/15. Belgrad 1982. 


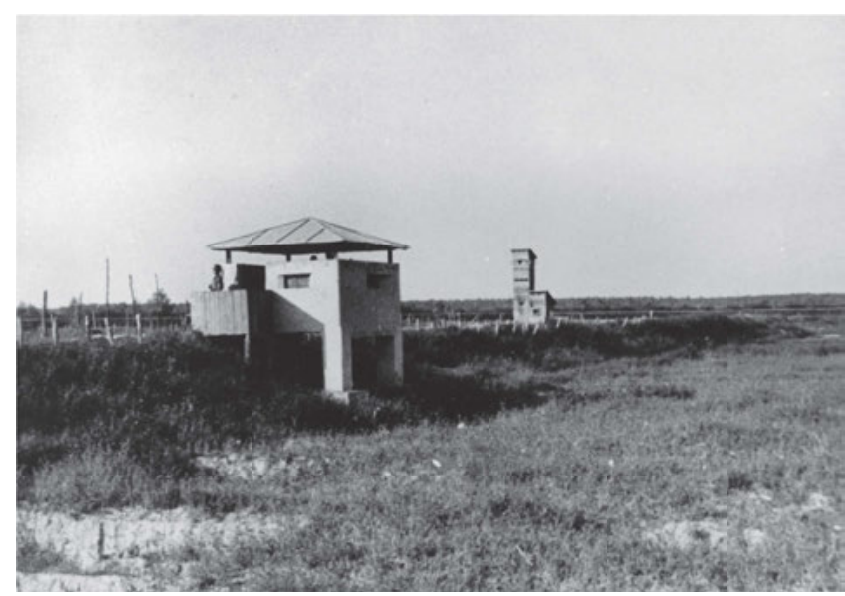

Aussichtsturm des Konzentrationslagers Jasenovac. Fotograf unbekannt. Sarajevo, Historisches Museum von Bosnien und Herzegowina | FNOB 2029.

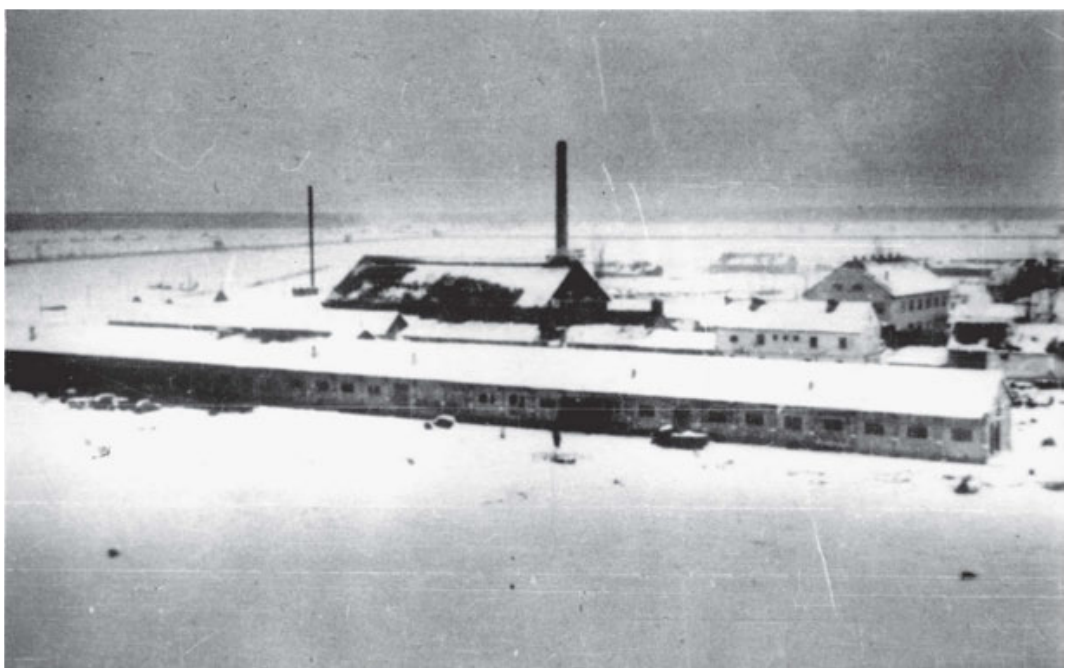

Konzentrationslager Jasenovac im Winter. Fotograf unbekannt. Jerusalem, Yad Vashem | 42913.

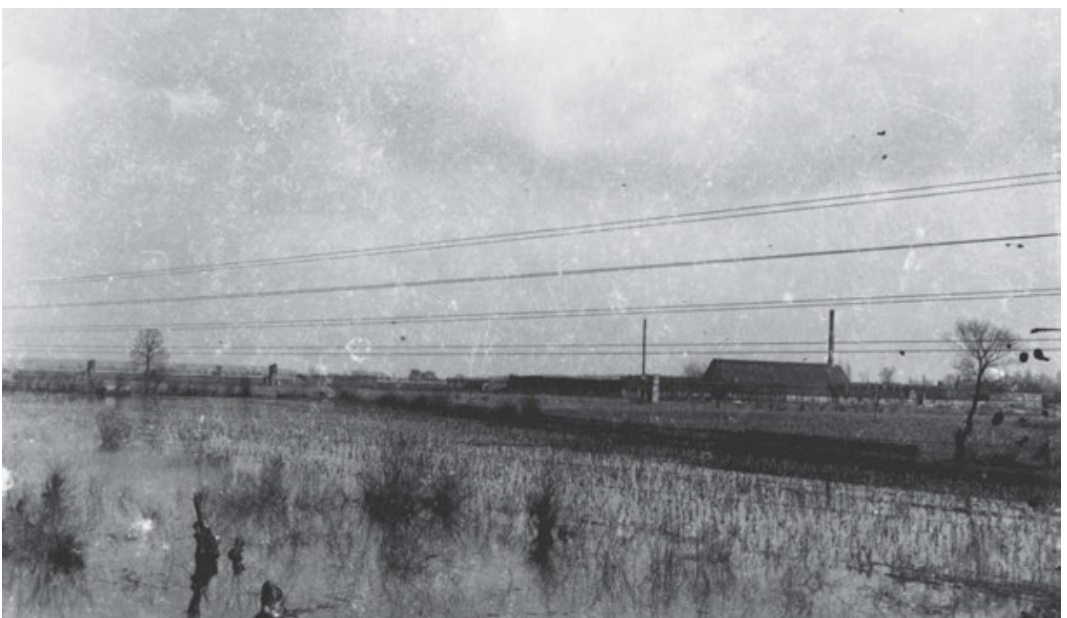

Konzentrationslager Jasenovac. Foto: Mato Djukić. JUSP Jasenovac. 
Pavićs Aufnahmen der Befreiung der Stadt Zagreb - vor der eigentlichen Befreiung am 8. Mai - gelten als die bedeutendsten Fotografien der Stadt. In diesen acht Tagen zogen laut Augenzeugenberichten Tschetniks, verschlagene Einheiten der deutschen Wehrmacht, Zivilisten, Soldaten der Landwehr und der Ustascha durch die Stadt, während die Bürger in unbeschreiblicher Angst lebten. Fotografien der Befreiung der Stadt nahm auch der Zagreber Untergrundkämpfer Stjepan Puba Cerjan auf, den man beinahe verhaftet hätte, als er sich vor dem Aufbruch zu den Partisanen von seinen Eltern verabschieden wollte. ${ }^{42}$ Neben Cerjan erhielt nur noch Tošo Dobac die Erlaubnis, den Einmarsch der Partisaneneinheiten festzuhalten, der jedoch kritisch und mit einer gewissen Distanz an das Fotografieren heranging.

Die ersten Aktionen an der Befreiungsfront in Ljubljana nahmen die Fotografen Miran Pavlin, Dr. Jakob Prešern, ${ }^{43}$ Viktor Kramer und Jože Stajer auf, deren Filme man den Partisaneneinheiten auf dem befreiten Territorium schickte. Ähnlichen Tätigkeiten gingen auch Fotografen in anderen Städten nach. ${ }^{44}$ In Ljubljana wurde Ende April 1941 die Antiimperialistische Front ins Leben gerufen, die bereits kurze Zeit in Widerstandsfront des slowenischen Volkes umbenannt wurde. Sie agierte illegal, organisierte den Druck von propagandistischen Flugblättern, während ihre Fotografen zugleich technische Arbeiten erledigten und Bilder für gefälschte Ausweise anfertigten. Besonders interessant ist, dass sich in Slowenien zahlreiche Fotostudios dazu entschlossen, das fotografische Material zu kopieren, welches die italienischen und deutschen Besatzungsmächte zur Entwicklung brachten. Eine solche Form der nachrichtendienstlichen Tätigkeit setzte bereits 1941 ein. Auf Weisung des Dichters Karl Destovnik-Kajuh organisierte Stane Viršek eine Gruppe von 15 Personen, die diesen Tätigkeiten nachging. ${ }^{45}$ Edi Šelhaus dokumentierte in Škofija Loka auf dieselbe Weise die Verbrechen der Besatzungsmächte, ${ }^{46}$ während es in Celje dem offiziellen Fotografen der deutschen Wehrmacht Josip Pelikan gelang, Fotografien der Erschießung von Zivilisten in Stari Pisker zu kopieren. Bis zum heutigen Tag konnte nicht abschließend geklärt werden, von wem und wie diese Aufnahmen gemacht wurden. Doch Pelikan ist es zu verdanken, dass dieses Archiv, welches die Schrecken während der deutschen Okkupation der Stadt Celje dokumentiert, noch immer existiert, obwohl er selbst die ganze Zeit für die deutschen Besatzungsmächte gearbeitet hatte.

Stari Pisker ist heute Teil des Gefängnisses in Celje, dessen Hof als Gedenkstätte für die Öffentlichkeit zugänglich ist. In den Kriegsjahren waren wahrscheinlich mehr als 10.000 Menschen in dem Gefängnis inhaftiert, in seinem Hof fanden insgesamt sechs Mal Erschie-

\footnotetext{
42 Cerjan, Stjepan. Ustaj, evo ustaša!. In: Tihić, Esad (Hrsg.). Revolucionarni omladinski pokret u Zagrebu 1941-45. Bd. II. Zagreb: Gradska konferencija SSRNH, Gradski odbor Saveza udruženja boraca NOR-a, Sveučilišna naklada Liber 1984, S. 95.

43 Fabec, Franc. Photography during the Slovene National Liberation Struggle. In: Pirjevec, Jože und Repe, Bože (Hrsg.). Resistance, Suffering, Hope: The Slovene Partisan Movement 1941-1945. Ljubljana: National Committee of Union of Societes of Combatants of the Slovene National Liberation Struggle Ljubljana, Triest: Založništvo tržaškega tiska Trieste in Kooperation mit Slovenska kulturno gospodarska zveza 2008, S. 95

44 Ein detailliertes Namensverzeichnis ist folgendem Buch zu entnehmen: Fabec, Franc und Vončina, Dejan. Slovenska odporniška fotografija 1941-1945. Ljubljana: Modrijan 2005.

45 Ebd., S. 23.

46 Fabec, Franc. Photography during the Slovene National Liberation Struggle. In: Pirjevec, Jože und Repe, Bože (Hrsg.). Resis tance, Suffering, Hope: The Slovene Partisan Movement 1941-1945. Ljubljana: National Committee of Union of Societes of Combatants of the Slovene National Liberation Struggle Ljubljana, Triest: Založništvo tržaškega tiska Trieste in Kooperation mit Slovenska kulturno gospodarska zveza 2008, S. 95.
} 


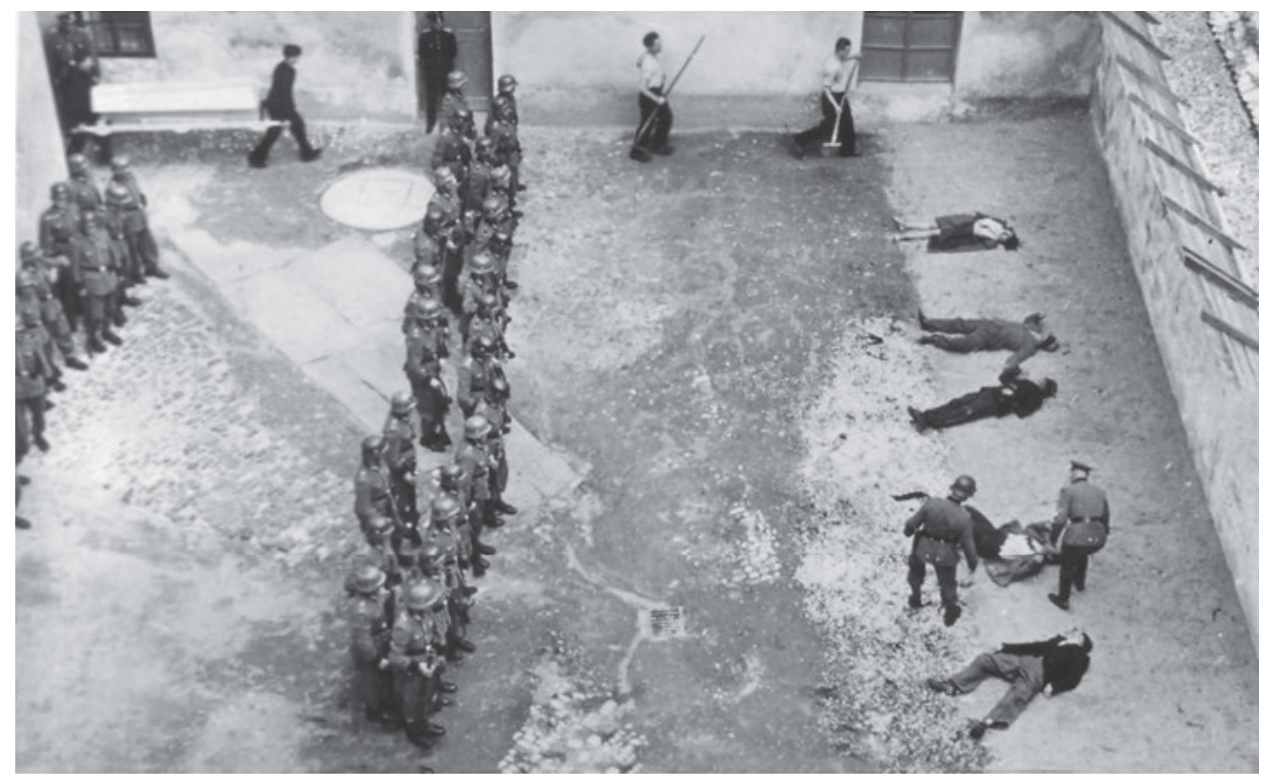

Erschießungskommando in Celje, Juli 1942. Fotograf unbekannt. Ljubljana, Museum für Neuere Geschichte Sloweniens I VF 96.

ßungen von Gefangenen statt. Das größte Verbrechen ereignete sich am 22. Juli 1942, als die Einheiten der SS als Vergeltungsmaßnahme alle Inhaftierten hinrichteten. Im Museum der neueren Geschichte der Stadt Celje werden heute ihre Abschiedsbriefe verwahrt, die ein erschütterndes Zeugnis der nationalsozialistischen Brutalität darstellen.

Pelikan hatte 1942 auch Aufnahmen von der sogenannten Beschämung der Partisanen, das heißt der öffentlichen Zurschaustellung ihrer Leichen, gemacht. Ihre Kameraden mussten vor den Leichen stehen und Aufschriften mit erniedrigendem Inhalt in den Händen halten, während Bürger und deutsche Soldaten an ihnen vorbeigingen. Auf einer der Fotografien ist Tončka Čeč zu sehen, die bereits in der Vorkriegszeit Kommunistin war und unter dem Decknamen Roza der Antifaschistischen Front angehörte. Sie starb am 3. November 1943 an den Folgen ihrer Typhuserkrankung im Konzentrationslager Auschwitz. Eine ihrer Fotografien ist besonders eindrücklich:

"Leichen liegen auf dem Kopfsteinpflaster, während Zivilisten und deutsche Soldaten an ihnen vorbeigehen. Gelassen wirken nur die Herrschaften in Anzügen. Sie unterhalten sich. Ihre Körper wirken nicht verkrampft. Pelikan ist adrett angezogen, fokussiert und achtet auf die Komposition. Er entschied sich für eine Totalaufnahme, achtete jedoch auf die Toten, die noch Lebenden und die Gequälten. All sie nahm er in seiner Einstellung auf. Man erlaubte ihm, den geschützten Teil hinter der gespannten Schnur zu betreten. Er bewegte das Objektiv nach rechts und richtete es auf die Frau, deren Gesicht man nur schwer vergessen kann. Sie hob ihren Kopf leicht an und drehte inn nach links. Sie stand nunmehr hocherhobenen Hauptes. Man spürte ihre Kraft, obwohl ihr die Hände gebunden waren. « ${ }^{47}$ 
In Serbien war während der gesamten Kriegsdauer die illegale Druckerei des Zentralkomitees der Kommunistischen Partei Jugoslawiens tätig und gab die Zeitung Jedinstvenog narodno-oslobodilačkog fronta Srbije (Stimme der Vereinigten Volksbefreiungsfront Serbiens)

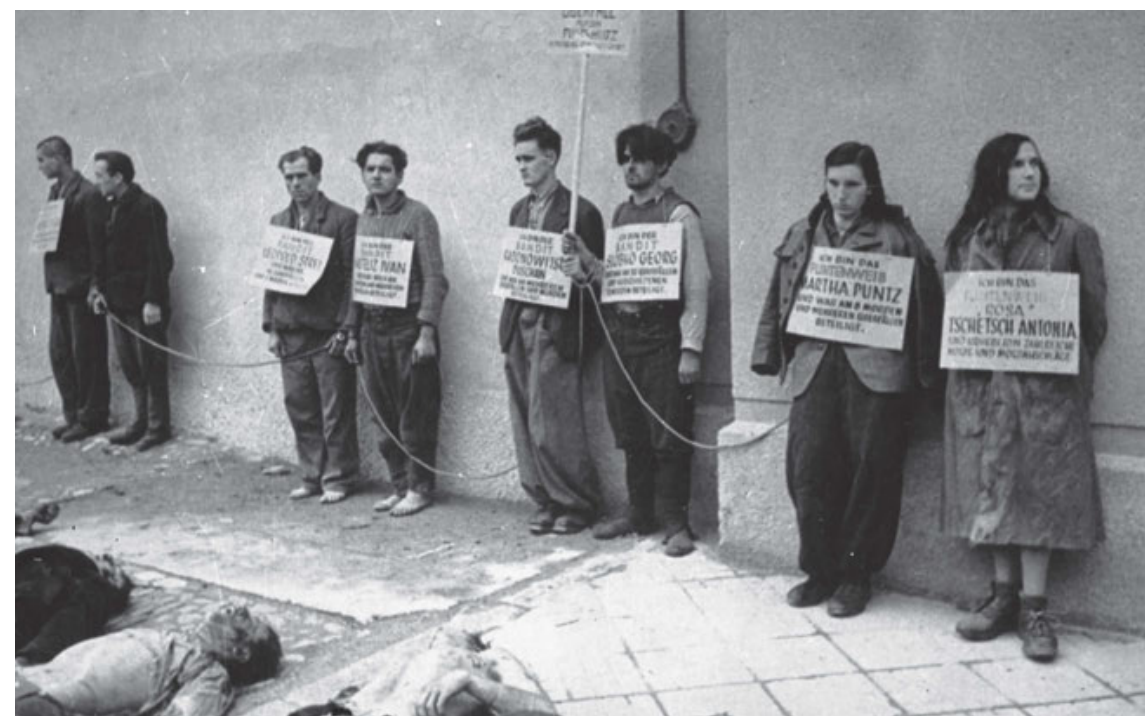

Die slowenische Kommunistin Tončka Čeč mit Mitgefangenen (rechts im Bild: Antonia Tschetsch). Fotograf unbekannt. Ljubljana, Museum für Neuere Geschichte der Stadt Celje. Ohne Inv.-Nr.

heraus. Mit der Druckerei arbeiteten zahlreiche Mitglieder und Sympathisanten der antifaschistischen Bewegung zusammen - Schriftsteller, Künstler und Journalisten. Trotz zahlreicher Verhaftungen blieb die Druckerei vom Kriegsausbruch bis zum 28. Juli 1944 aktiv, als die Gestapo und die Gendarmerie der Kollaborationsregierung die Räumlichkeiten der Druckerei stürmten, die zu jener Zeit in der Daničareva-Straße 24 untergebracht war. Die Druckereimitarbeiter Slobodan Jović und Branko Djonović vernichteten zuerst vertrauliche Dokumente, um dann ihre Pistolen zu ziehen und gegen die Polizisten zu kämpfen. In der Falle sitzend und sich dessen bewusst, dass man sie gefangen nehmen würde, gaben die beiden Freunde gegenseitig tödliche Schüsse ab, um nicht lebend in die Hände der Polizei zu fallen. Beim selben Anlass kam auch das Ehepaar Ratka und Milutin Blagojević ums Leben. ${ }^{48}$

Die deutsche Wehrmacht verübte im besetzten Jugoslawien Massenhinrichtungen, die dann von der in diesen Gegenden seit Oktober 1941 präsenten Propaganda-Abteilung Südost dokumentiert wurden. Stationiert in Belgrad, sollten sie Propagandamaterial für die lokale

47 Konjikušić, Davor. Nacistički zločini celjski. In: Novosti, Nr. 746, 07.04. 2014. Siehe http://arhiva.portalnovosti.com/2014/04/ nacisticki-zlocini-celjski/ [Aufruf am 07.02.2021].

48 Radanović, Milan. llegalna štamparija Pokrajinskog komiteta KPJ za Srbiju Daničareva 24. In: Pisarri, Milovan und Rädle, Rena (Hrsg.). Mesta stradanja i antifašističke borbe u Beogradu 1941-1944. Priručnik za čitanje grada. Belgrad: Rosa Luxemburg Stiftung Southeast Europe 2016, S. 109-111. 
Bevölkerung produzieren. ${ }^{49}$ Innerhalb der deutschen Truppen war die fotografische Produktion von Beginn an hierarchisch gegliedert: von der Versorgung mit Fotomaterial über die Aufnahme von Fotografien, die Entwicklung von Negativen und die Anfertigung von Abzügen bis hin zur Distribution der Bilder. In dem als vertraulich gekennzeichneten Dokument der Gegenspionageabteilung des Heereskommandos vom 28. November 1941 ist zu lesen, dass es ausdrücklich verboten war, die Gesichter der zum Tode durch Erschießung verurteilten Personen zu fotografieren:

"1. Das Fotografieren der Erschießungen infolge der standgerichtlichen Urteile ist grundsätzlich verboten. Wenn in besonders begründeten Ausnahmefällen die Anfertigung von Fotografien zu rein militärischen Zwecken notwendig sein sollte, kann die Genehmigung nur von einem Offizier erteilt werden, der mindestens den Rang eines Divisionskommandeurs besitzt. Die aufgenommenen, noch nicht entwickelten Filme sind mit der Aufschrift >Vertraulich der Wehrmacht/Amtsgruppe für Wehrmachtspropaganda zusammen mit dem Antrag auf Zustellung bestimmter Bilder zu schicken.

2. Militärische Organe, denen die Durchführung solcher Erschießungen befohlen wurde, sind verpflichtet, jedes Mal zwecks Ausführung dieses Befehls alle notwendigen Vorsichtsmaßnahmen zu treffen und Schaulustige fernzuhalten. Die bei solchen Anlässen bereits vorher erfolgten Aufnahmen und Negative sind aus dem Verkehr zu ziehen und, wenn dies möglich ist, an das Oberkommando des Heeres zu schicken."

Bei deutschen Soldaten fand man oftmals Aufnahmen von Verbrechen, Trophäenfotografien, die einzelne Soldaten als Beweis in den Kämpfen gegen "Banditen"sammelten - eine Bezeichnung für die Partisaneneinheiten, deren Anerkennung als legitime militärische Organisation systematisch abgelehnt wurde. Unter den deutschen Soldaten war es sehr verbreitet, Fotoalben anzulegen, in denen Deportationen, Erschießungen, öffentliche Hinrichtungen durch Erhängen und Erniedrigungen der okkupierten Völker dokumentiert wurden, wodurch man die gerade verübten Gewaltverbrechen vervollständigte. ${ }^{50}$ Ein Beispiel für diese Praxis ist die Ansichtskarte mit drei erhängten Zivilisten unter dem Titel »Blühende Bäume, Serbien 1941.$^{51}$ Die deutschen Soldaten schickten zudem in den Briefen an ihre Angehörigen in Deutschland verschiedene Trophäenfotografien der begangenen Verbrechen, obwohl sie damit gegen den Paragraphen 25 des Militärstrafgesetzbuches verstießen, der eine solche Vorgehensweise als Missachtung des Militärgeheimnisses sowie als Landesverrat im Sinne der Paragraphen 90d und 90e des Reichsstrafgesetzbuches sanktionierte. ${ }^{52}$ Im Museum für Neuere Geschichte Sloweniens in Ljubljana befindet sich ein gut erhaltenes, sorgfältig erstelltes Fotoalbum eines Offiziers der SS, in dem in linearer Montage Fotografien der an den Partisanen verübten Verbrechen angeordnet sind.

49 Uziel, Daniel. The Propaganda Warriors: The Wehrmacht and the Consolidation of the German Home Front. Oxford et al. Peter Lang 2008, S. 287.

50 Vitaljić, Sandra. Rat slikama. Suvremena ratna fotografija. Zagreb und Mostar: Algoritam 2013, S. 93.

51 Trials of War Criminals Before The Nuernberg Military Tribunals Under Council Law. Bd. XI, Nr. 10. United States Government Printing Office Washington 1950, S. 1147.

52 Manošek, Valter. Holokaust u Srbiji. Vojna okupaciona politika i uništavanje Jevreja 1941-1942. Belgrad: Službeni list SRJ 2007,

S. 90. 
Manchmal wurden solche Fotografien zu besonderen Trophäen wie eine Aufnahme des deutschen SS-Bataillons im slowenischen Dorf Masor, in dem zwei Zivilisten und drei Partisanen getötet wurden, oder die Fotografie vom 20. März 1945 aus dem Dorf Sedej in der Nähe von Idrijske Krnice. Ein Bericht des Stabs der Dritten operativen Zone vom 23. Mai 1943, der sich an den Hauptstab der Volksbefreiungsarmee und der Widerstandsbewegung Kroatiens richtete und die Arbeit des Geheimdienstes dokumentierte, enthält die Information, dass im Zuge des Angriffs auf Slavonski Zdrug nahe Voćin bei den gefangengenommenen Offizieren Fotografien der begangenen Verbrechen gefunden wurden. ${ }^{53}$ Ähnliche Fotos entdeckte man auch bei anderen deutschen Offizieren, insbesondere im Kozara-Gebirge. ${ }^{54}$

Das Erhängen von Zivilisten, zumeist als Vergeltungsaktion, war auf dem Territorium Jugoslawiens allgegenwärtig. Doch eines der brutalsten Beispiele für die verübten Verbrechen stellt die massenhafte Hinrichtung und Erschießung auf dem städtischen Friedhof in

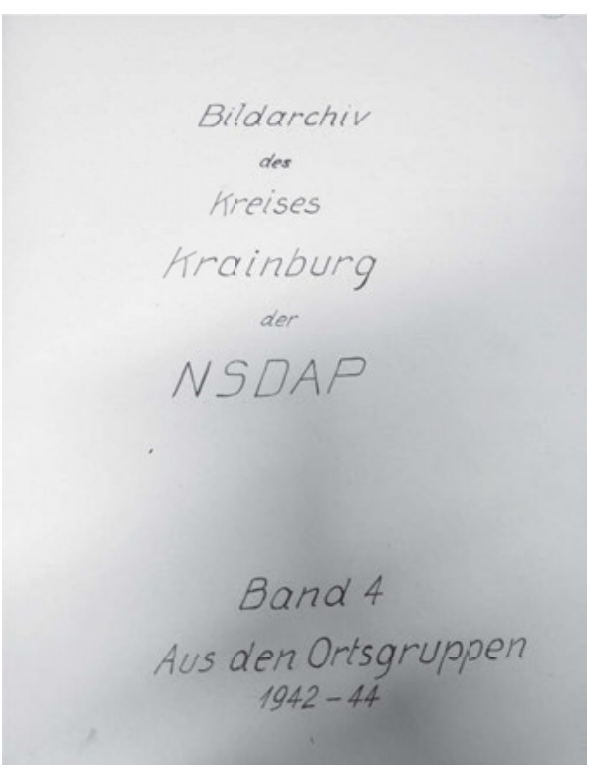

Album Bildarchiv des Kreises Krainburg der NSDAP. Ljubljana, Museum für Neuere Geschichte Sloweniens. Ohne Inv.-Nr.

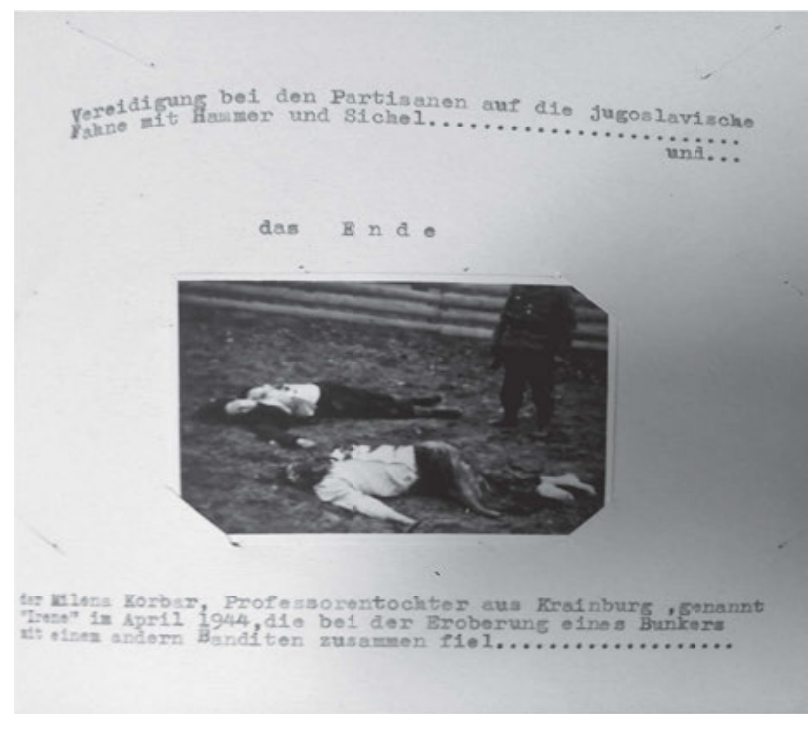

Album Bildarchiv des Kreises Krainburg der NSDAP. Ljubljana, Museum für Neuere Geschichte Sloweniens. Ohne Inv.-Nr. 


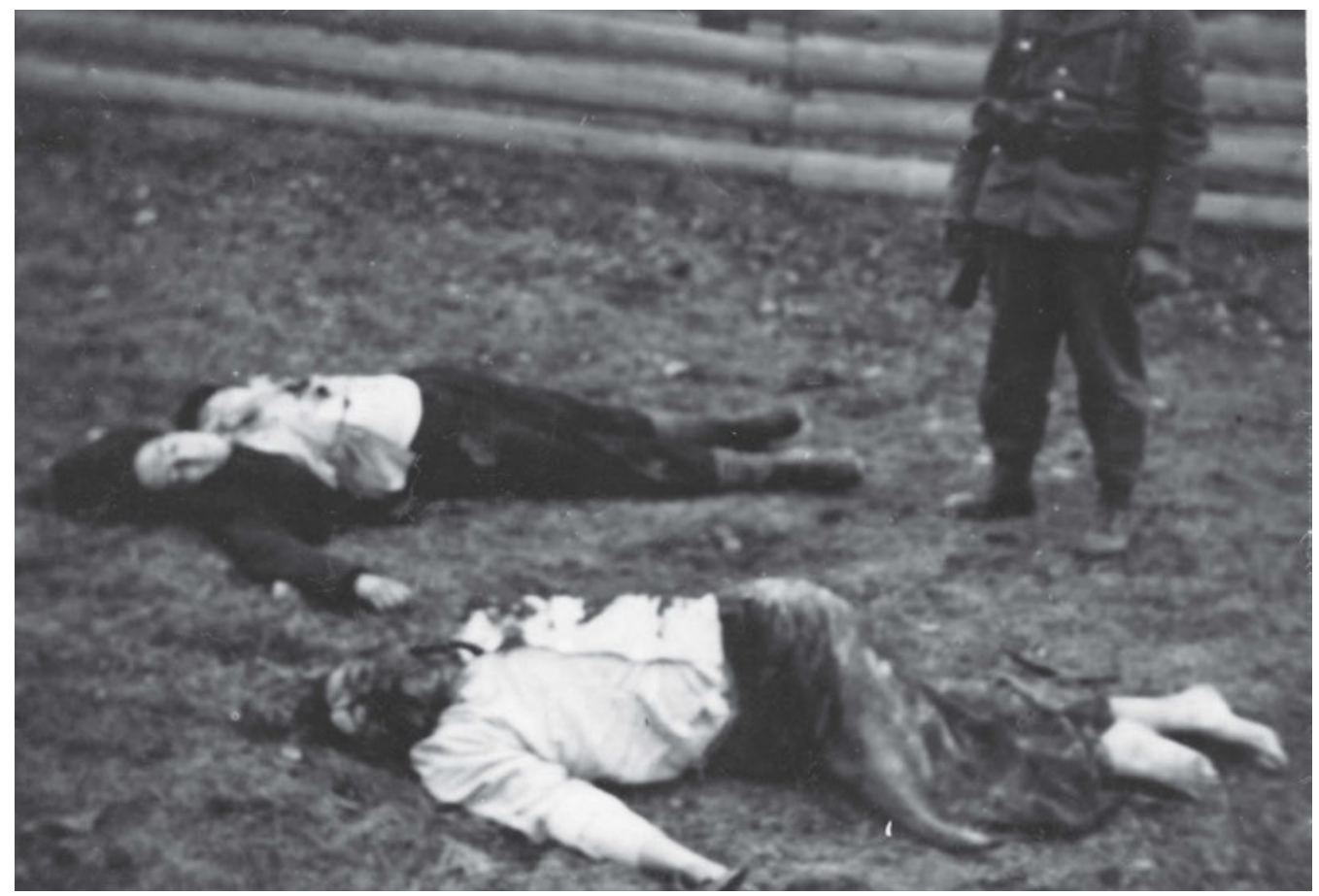

Detail aus dem Album Bildarchiv des Kreises Krainburg der NSDAP. Ljubljana, Museum für Neuere Geschichte Sloweniens. Ohne Inv.-Nr.

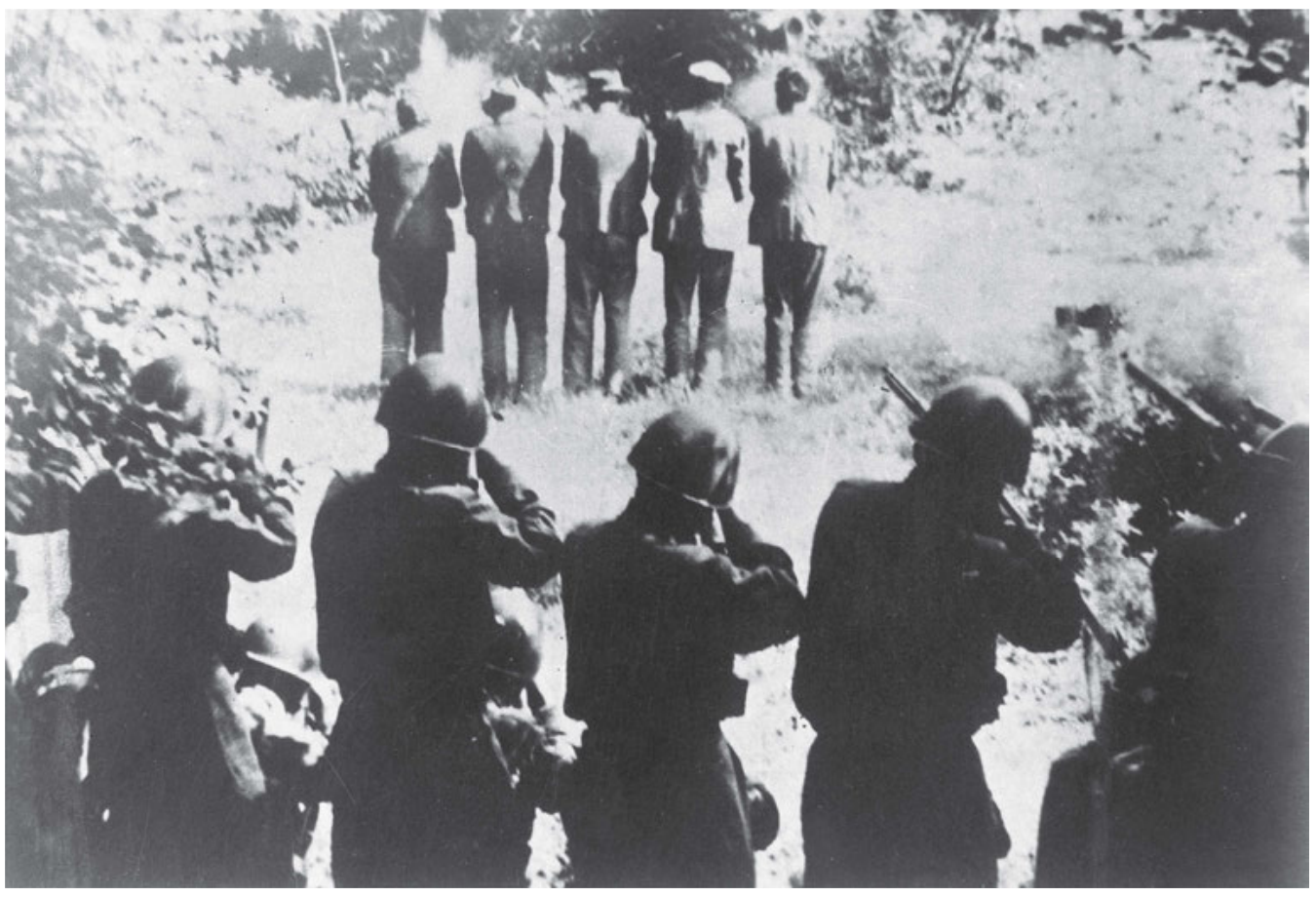

Erschießung von Gefangenen. Von links: Franc Žnidaršić, Janez Krajc, France Škerbec, Feliks Žnidaršić, Edvard Škrebec. Križna gora im Loški Tal, Slowenien, 31. Juni 1942. Fotograf unbekannt. Ljubljana, Museum für Neuere Geschichte Sloweniens | 1818. 


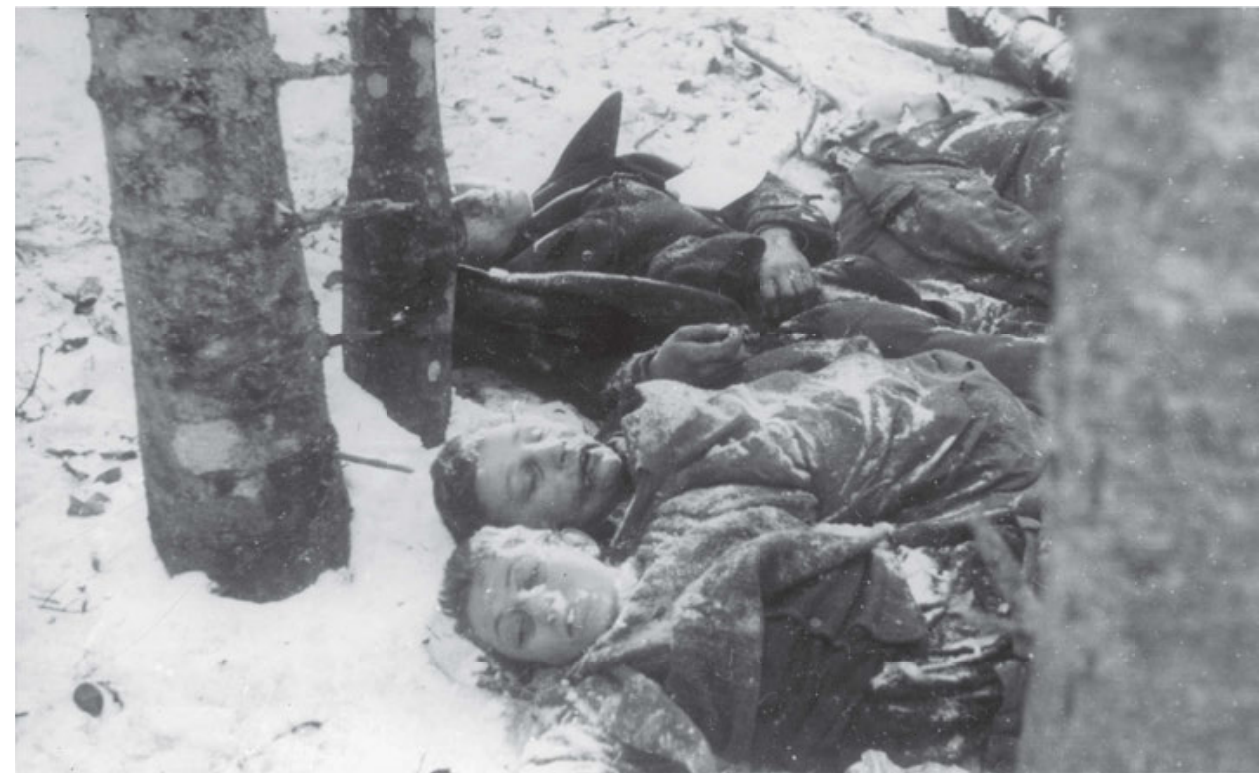

Gefallene Kämpfer des Pohorski Bataillons, 8. Januar 1943. Fotograf unbekannt. Ljubljana, Museum für Neuere Geschichte Sloweniens | 4973/9.

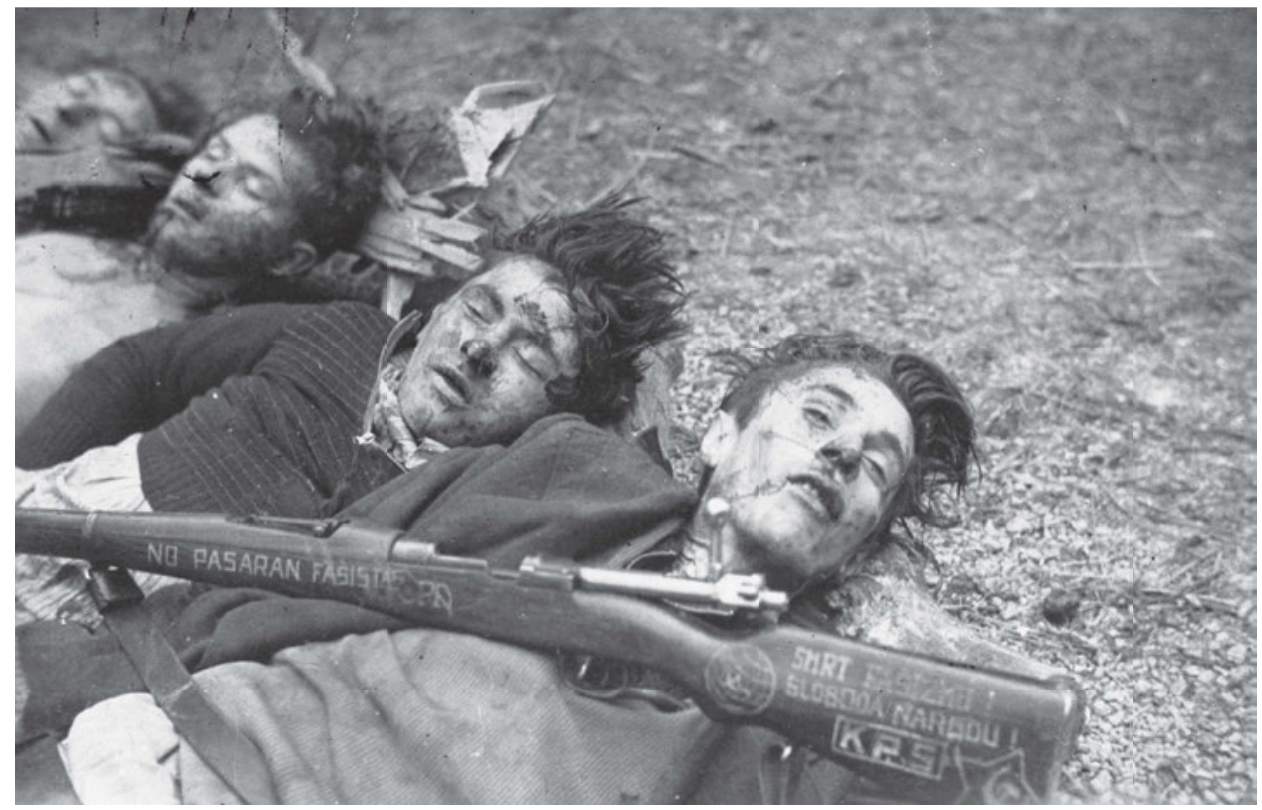

Vier gefallene Kämpfer der Brežiške-Kompanie, 28. November 1941. Von links: Ivan Milavec, Marjan Cerjak, Draško Hlebec und Milan Kovačić. Fotograf unbekannt. Ljubljana, Museum für Neuere Geschichte Sloweniens | pl8864a. 

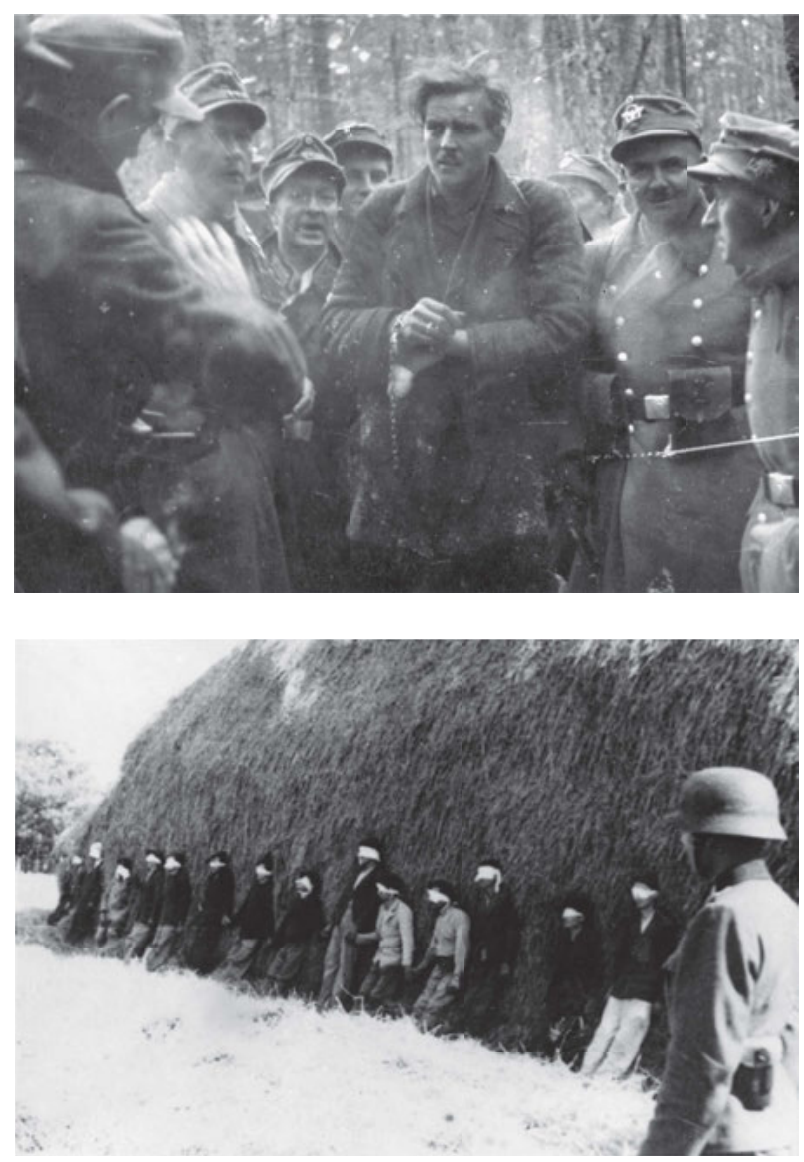

Franc Kunaver, gefangener Kämpfer des PohorskiBataillons, umgeben von deutschen Polizisten. Pohorje, Slowenien, 8. Januar 1943. Foto: Ordelt Delti. Ljubljana, Museum für Neuere Geschichte Sloweniens | Di1085/1.

Erschießung von 17 Kommunisten in Smederevska Palanka, Serbien, 1941. Fotograf unbekannt. Belgrad, Militärmuseum | 1069.

Pančevo am 22. April 1941 dar, die Gerhard Gronefeld, Fotograf der deutschen PropagandaKompanie, aufgenommen hat. Ein zweites Mitglied dieser Einheit, Gottfried Kessel, hat die Hinrichtungen am Galgen und durch das Erschießungskommando mit seiner Filmkamera in Farbe festgehalten. Es sind Fotografien, über die Gronefeld viele Jahre später sagte, sie würden ihn sein Leben lang verfolgen. ${ }^{55}$ Anschließend kam es zu weiteren Demütigungen; die Leichen wurden den Menschenmassen und Soldaten zur Schau gestellt, wobei man den Toten nach der Hinrichtung Kopfbedeckungen aufsetzte, weil sie erst tot und gehängt $\mathrm{zu} » H e r r e n$ « geworden waren - wie im Fall der Kommunarden, deren Leichen nach der Pariser Kommune öffentlich ausgestellt und fotografiert wurden. Dasselbe Schicksal widerfuhr den slowenischen Kommunisten, die man öffentlich vor den auf dem Boden liegenden Leichen ihrer Kameraden demütigte. Öffentliche Hinrichtungen am Galgen und Erschießungen waren Methoden, um die Bevölkerung zu terrorisieren; Vergeltungsaktionen und Massenhinrichtungen wurden vor allem in Süd- und Osteuropa praktiziert, wo ein Großteil der Bevölkerung unter die Rassengesetze fiel. Die Aufnahmen dieser Exekutionen dienten als 
Beweis für die Durchführung militärischer Weisungen, ${ }^{56}$ besaßen aber auch die Funktion zusätzlicher Demütigung. Im Verlauf der Geschichte waren öffentliche Hinrichtungen am Galgen vor allem für nichtprivilegierte Gesellschaftsgruppen und die Population aus niedrigeren Schichten bestimmt. ${ }^{57}$

Die entsetzlichen Fotografien der Hinrichtung des 17-jährigen Mädchens Lepa Radić gehören vielleicht zu den bekanntesten Fotografien der Schreckensherrschaft und wurden mit der Zeit zum Symbol der auf jugoslawischem Territorium begangenen Verbrechen. Als Mitglied der Zweiten Krajina-Kompanie war die Krankenschwester Radić für die Evakuierung der Verwundeten und der Zivilbevölkerung während der Vierten feindlichen Offensive im Jahr 1943 zuständig. In den Abendstunden des 8. Februars 1943 entdeckten die Einheiten der berüchtigten Siebenten SS-Gebirgs-Division Prinz Eugen ihre Flüchtlingskolonne. Nachdem Radić auch die letzte Kugel aus ihrer Waffe abgefeuert hatte, schlug man sie mit Ge-

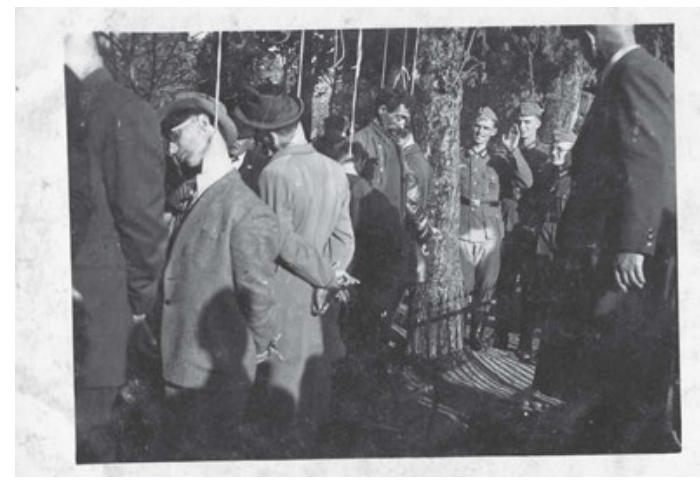

Gehängte Zivilisten am 22. Juni 1941 in Pančevo, Serbien. Das Bild wurde bei einem getöteten deutschen Soldaten entdeckt. Fotograf unbekannt. Jerusalem, Yad Vashem | 8053985.

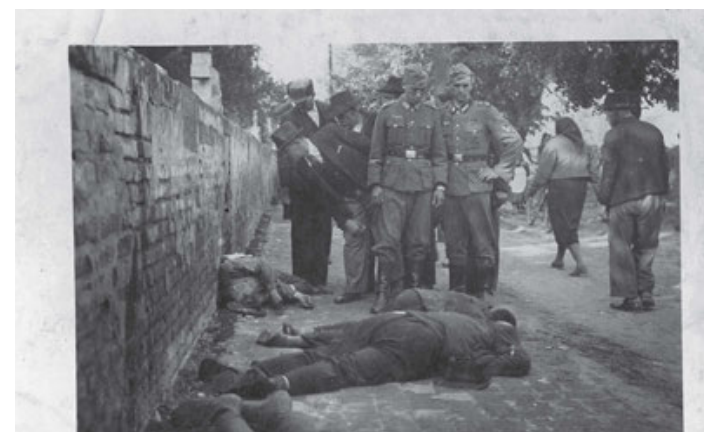

Erschießung von Zivilisten in Pančevo, Serbien, am 22. Juni 1941. Das Bild wurde bei einem getöteten deutschen Soldaten entdeckt. Fotograf unbekannt. Jerusalem, Yad Vashem I 8053996.

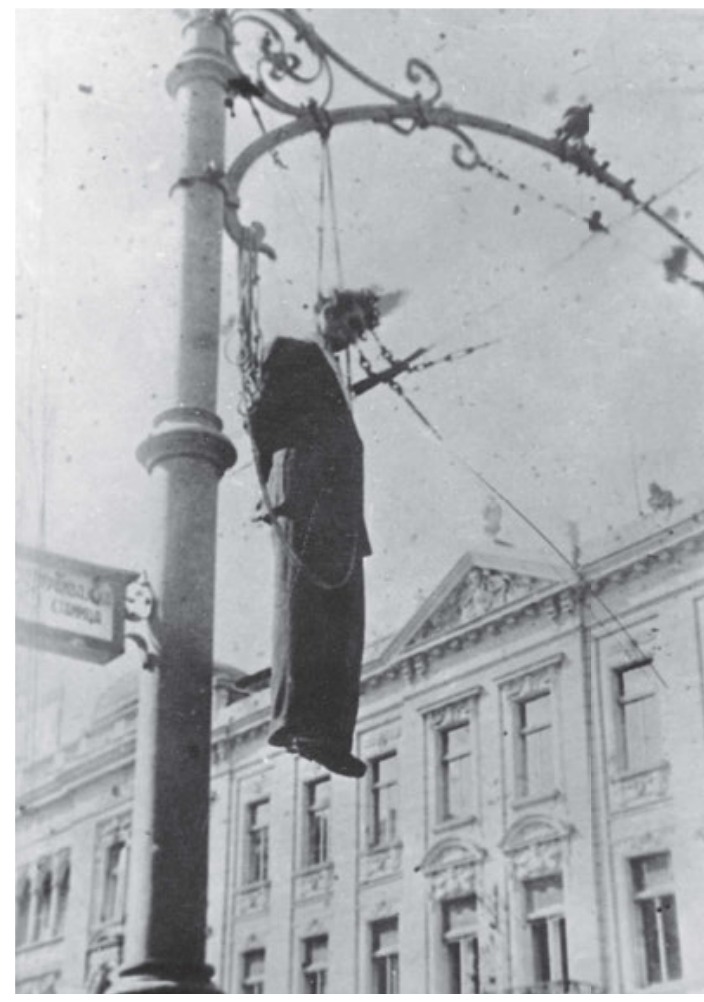

Jovan Janković, Schneider aus Belgrad, den deutsche Besatzungstruppen am 17. August 1941 am Terazije-Platz in Belgrad hängten. Belgrad, Militärmuseum | 1022.

56 Horvatinčić, Sanja. Ballade of the Hanged: The Representation of Second World War Atrocities in Yugoslav Memorial Sculpture. In: Unetič, Ines et al. (Hrsg.). Art and its Responses to Changes in Society. Cambridge: Cambridge Scholar Publishing 2016, S. $188-189$.

57 Ebd., S. 190. 

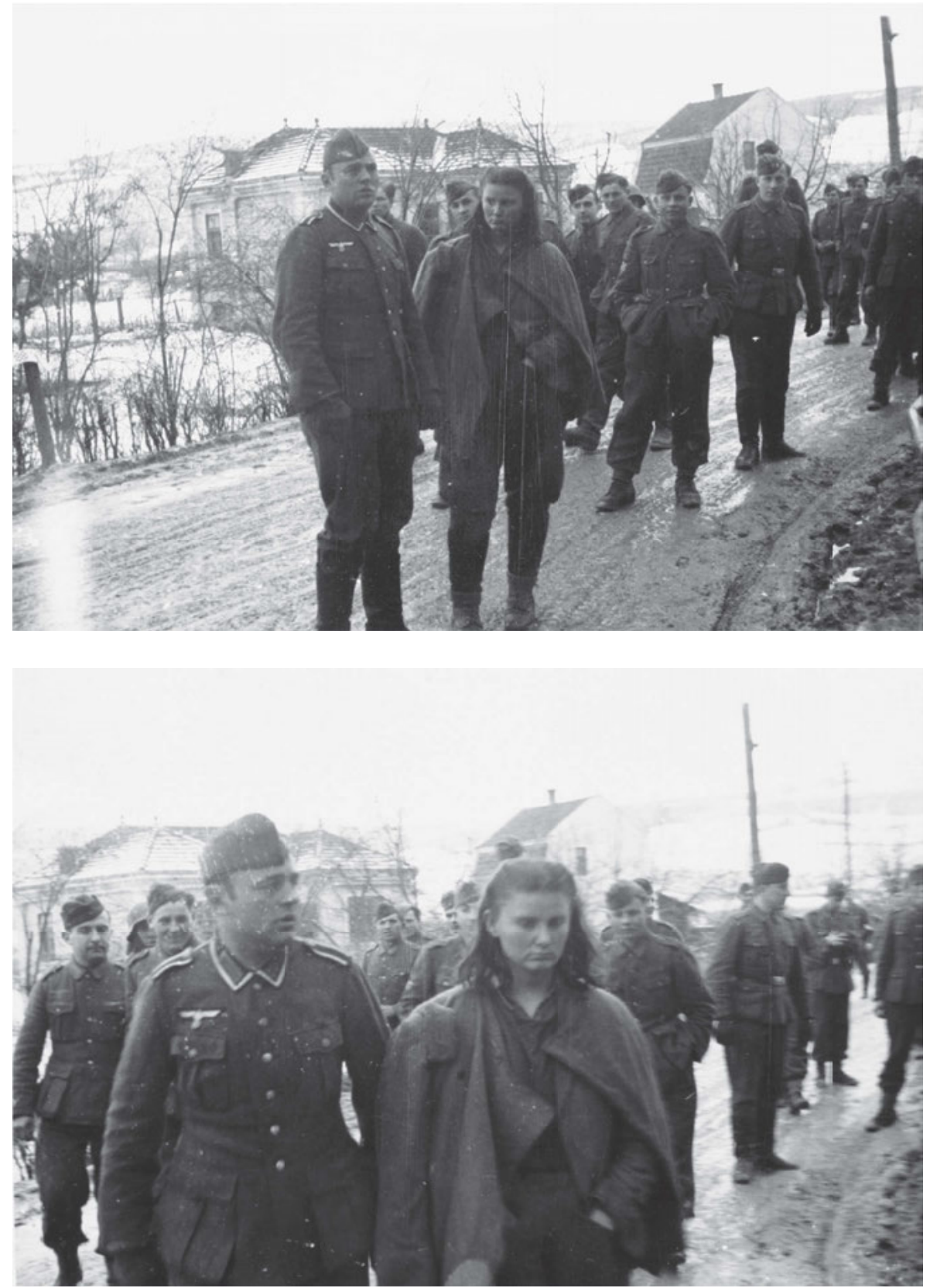

Die 17-jährige Volksheldin Lepa Radić vor ihrer Hinrichtung im Februar 1943 in Bosanska Krupa, Bosnien und Herzegowina. Fotograf unbekannt. Die Fotografie ist eine Schenkung von Dragoje Lukić.

wehrkolben zusammen und führte sie nach Bosanska Krupa ab, wo man sie nach drei Tagen in Gefangenschaft unter einem Akazienbaum unweit des Bahnhofs öffentlich am Galgen hinrichtete.

Der Kunsthistoriker Dragoje Lukić, der sich eingehend mit den Morden an Kindern und Zivilisten aus der Bosanska Krajina beschäftigte, veröffentlichte 1968 in der Zeitschrift Ilustrovana Politika einen Artikel über Lepa Radić, in dem er aufdeckte, dass die Fotografien ihrer 
Hinrichtung bei einem deutschen Soldaten gefunden wurden, der bei der Befreiung von Zagreb in der Ilica-Straße gefallen war. Die Identität des Mädchens auf den Fotos blieb über viele Jahre unbekannt, doch dann erkannte sie eine Besucherin des Museums der Revolution in Mostar rein zufällig. ${ }^{58}$ Durch die aufgefundenen Fotografien, die der deutsche Soldat als Kriegstrophäe mit sich führte, wird heute die ganze Grausamkeit der öffentlichen Hinrichtung, die die junge Aktivistin der kommunistischen Partei erlitt, deutlich vor Augen geführt. Ihr Gesichtsausdruck wirkt fast verärgert, keine Spur von Angst ist zu sehen. Doch beim Blick auf das Mädchen, umgeben von einer Gruppe von Männern, die einige Augenblicke später ihrer Gefangenen, ihrer »Kriegsbeute« die Schuhe und die Jacke ausziehen und ihr das Leben nehmen werden, verspürt man ein Gefühl des Unbehagens und der Hilflosigkeit, und zwar gerade deshalb, weil in den Fotografien die ganze "Banalität des Bösen« zum Ausdruck kommt.

Entgegen ihrer ursprünglichen Funktion der Verängstigung der auf dem okkupierten Territorium lebenden Bevölkerung erzielten diese Fotografien in den Partisaneneinheiten eine gänzlich andere Wirkung. Sie hoben das heldenhafte Auftreten und die Aufopferung der Menschen hervor, die »trotz großer Risiken der Gewalt trotzten und als Indikator für die weit verbreitete Macht des Volkes und seiner Entschlossenheit dienten, sich der Widerstandsbewegung unter Anführung der Kommunistischen Partei Jugoslawiens anzuschließen
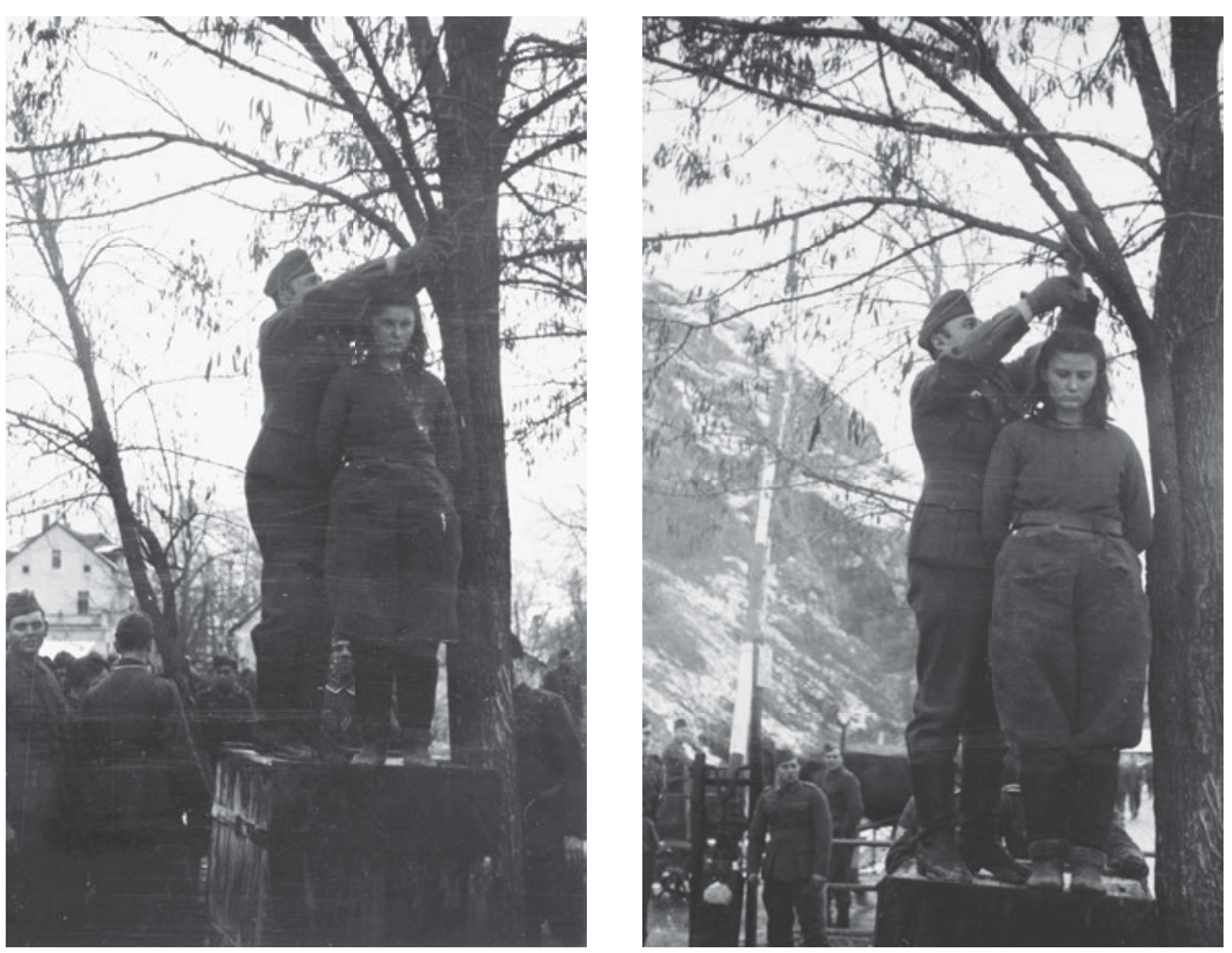

Hinrichtung der 17-jährigen Volksheldin Lepa Radić im Februar 1943 in Bosanska Krupa, Bosnien und Herzegowina. Fotograf unbekannt. Die Fotografien sind eine Schenkung von Dragoje Lukić.

58 Lukić, Dragoje. Lepa Radić 1943. nije imala ni 18 godina: Kako su otkriveni potresni snimci vešanja mlade partizanke. In: Yugopapir, März 1968. Siehe http://www.yugopapir.com/2017/10/lepa-radic-43-nije-imala-ni-18-godina.html [Aufruf am 07.02.2021]. 


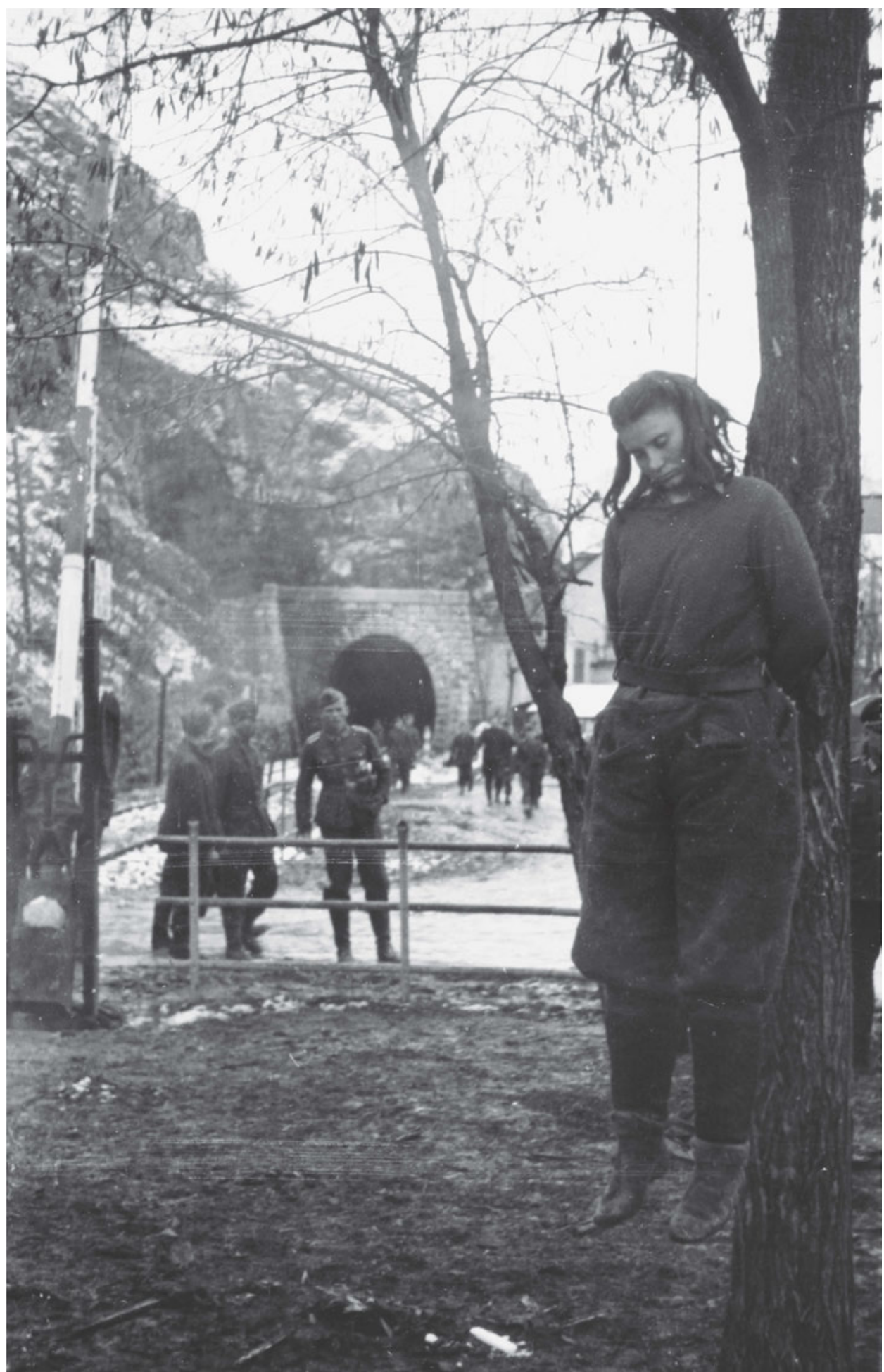

Hinrichtung der 17-jährigen Volksheldin Lepa Radić im Februar 1943 in Bosanska Krupa, Bosnien und Herzegowina. Fotograf unbekannt. Die Fotografie ist eine Schenkung von Dragoje Lukić. 
und sie zu unterstützen, die ihrerseits im Verlauf des Zweiten Weltkrieges die Fundamente der künftigen politischen und gesellschaftlichen Ordnung schuf.«59 Statt die Soldaten und Widerstandskämpfer zu verängstigen und einzuschüchtern, dienten diese Fotografien im Krieg dazu, sie zu noch größerem Widerstand gegen den Feind zu motivieren. Aus diesem Grund sollte auch nicht verwundern, dass Moša Pijade, Chef der vorübergehend eingesetzten Verwaltungsabteilung des Hauptstabs, bereits am 20. Oktober 1942 die Weisung erteilte, alle Belege für die feindlichen Verbrechen zu sammeln, und dabei betonte, dass Fotografien auch in Zagreb zu bekommen sind. ${ }^{60}$ Eines der ersten Beispiele für die Veröffentlichung von Fotografien, die die Henker selbst aufgenommen hatten, findet sich in der 15. Ausgabe der Zeitung Borba vom 29. November 1944, in der unter der Fotografie folgender Titel zu lesen war: "Lasst uns das Blut und die Leiden unserer Brüder aus dem slowenischen Küstenland rächen«. ${ }^{61}$

An dieser Stelle gilt es zu betonen, dass die Partisanenfotografie innerhalb der Partisanenbewegung entstanden ist, der die deutsche Besatzungsmacht zusammen mit ihren einheimischen Handlangern jegliches Recht auf Existenz absprach. ${ }^{62}$ Der einzige Ausweg aus dem Zustand, in dem sich die unter physischer Okkupation stehende Gesellschaft befand, war der bewaffnete Widerstand, um die zivilisatorischen und emanzipatorischen Errungenschaften der Menschheit zu wahren und für die Nachwelt zu erhalten. ${ }^{63}$ Die Partisanen stellten mit ihren Fotografien nicht den Tod in den Vordergrund, der bei den Nationalsozialisten und Faschisten hingegen fester Bestandteil der Ideologie und der Kultur war, wovon verschiedene Symbole wie Totenköpfe, Knochen und Messer, aber auch okkulte Rituale zeugen, die einige Nazis praktizierten. Schließlich betrachtete auch Hitler, zu dessen bevorzugten Opern Wagners Götterdämmerung zählte, den Tod als eine erhabene Form und sah die Aufgabe der Kunst darin, zur Pflege des Totenkults im nationalsozialistischen Deutschland beizutragen, weshalb es logisch erscheint, dass die Fotografien der eigenen toten Soldaten zu Propagandazwecken missbraucht wurden. Die Partisanen fotografierten indes niemals ihre eigenen Gefallenen, da der Tod in ihren Augen nicht Ausdruck des Stolzes, sondern der Niederlage war, was ein wichtiger praxeologischer Unterschied ist.

Aufnahmen der Erschießung gefangengenommener feindlicher Soldaten durch die Partisanen waren bereits seit 1941 durch unterschiedliche Befehle verboten worden. Eines der seltenen Beispiele bilden die Fotografien von Hugo Fischer Ribarić, die bei den Kämpfen um die Befreiung von Rijeka oberhalb von Vežice und unweit des heutigen astronomischen Zentrums entstanden sind. Als damals schon etablierter Fotograf wusste Fischer sicherlich, dass er gegen die existierenden Kriegsvorschriften verstieß, dennoch beschloss er, die Erschießung der deutschen Soldaten zu fotografieren und die Bilder zu veröffentlichen, höchstwahrscheinlich als Zeichen dafür, dass er mit dem Erschießungsbefehl nicht einverstanden war.

59 Ebd., S. 191.

60 Zbornik dokumenata i podataka o narodno-oslobodilačkom ratu jugoslovenskih naroda. Bd. II/6: Dokumenta vrhovnog štaba Narodnooslobodilačke vojske Jugoslavije 1942. Belgrad 1957.

61 Vitaljić, Sandra. Rat slikama. Suvremena ratna fotografija. Zagreb und Mostar: Algoritam 2013, S. 92.

62 Stojaković, Krunoslav. Revolucionarno nasilje u narodnooslobodilačkom ratu. In: Radanović, Milan (Hrsg.). Kazna i zločin: Snage kolaboracije u Srbiji. Belgrad: Rosa Luxemburg Stiftung 2014, S. 21.

63 Ebd., S. 24. 


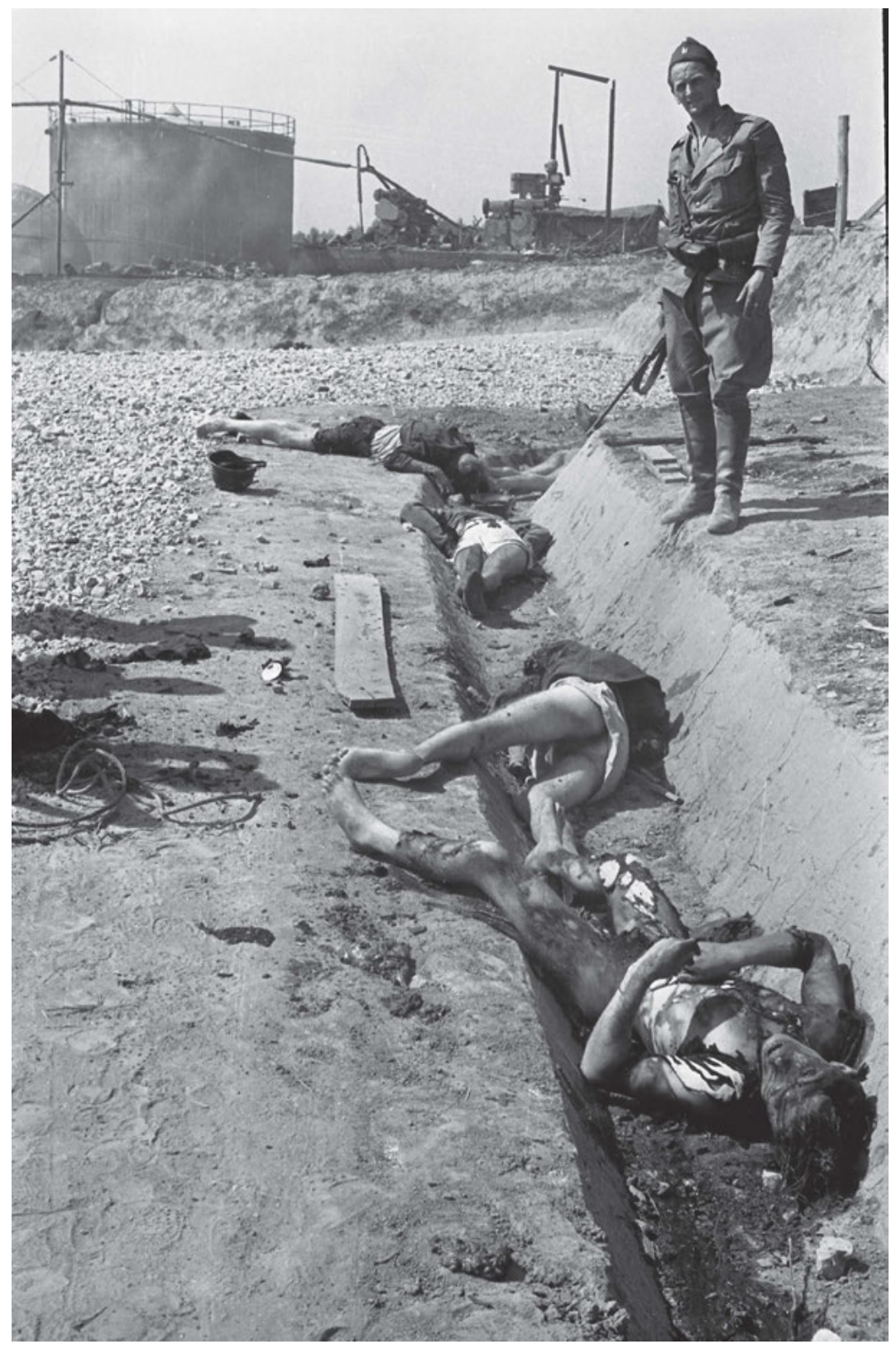

Nach einer Partisanenaktion in Gojlo, Kroatien, am 6. September 1942. Ein Ustascha-Soldat neben seinen Opfern. Foto: Dragutin Rajterić. Zagreb, Kroatisches Historisches Museum I HPM-MRNH-N-6751. 


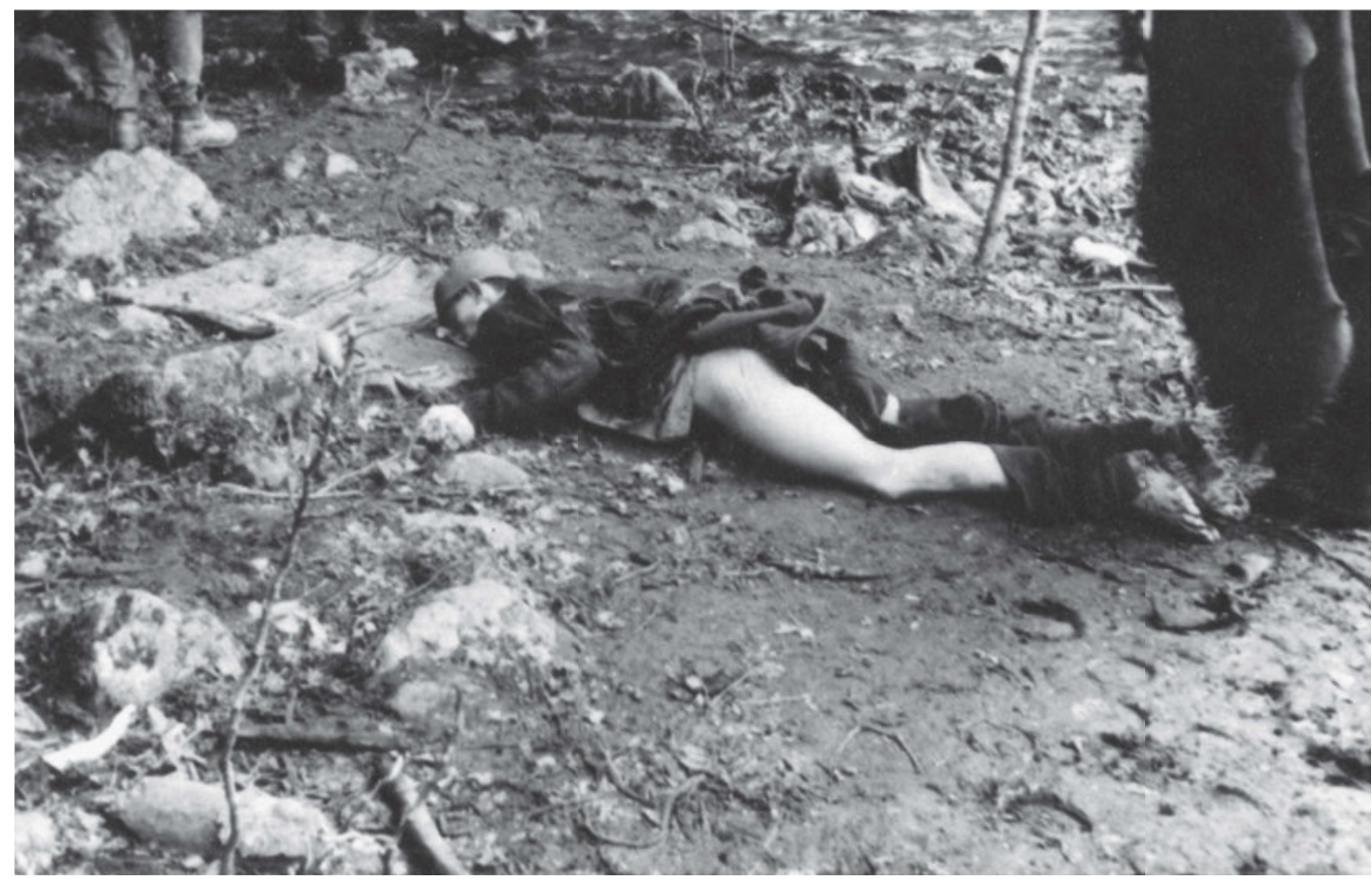

Unbekanntes Opfer, Bosnien und Herzegowina, 1943. Foto: Mladen Iveković.

Zagreb, Kroatisches Historisches Museum | HPM-MRNH-A-6337-165. 